\title{
The cnidarian origin of the proto-oncogenes NF-кB/STAT and WNT-like oncogenic pathway drives the ctenophores (Review)
}

\author{
JOSEPH G. SINKOVICS \\ St. Joseph Hospital's Cancer Institute Affiliated with the H.L. Moffitt Comprehensive Cancer Center; \\ Department of Molecular Medicine, The University of South Florida Morsani College of Medicine, Tampa, FL, USA
}

Received June 15, 2015; Accepted June 26, 2015

DOI: 10.3892/ijo.2015.3102

\begin{abstract}
The cell survival pathways of the diploblastic early multicellular eukaryotic hosts contain and operate the molecular machinery resembling those of malignantly transformed individual cells of highly advanced multicellular hosts (including Homo). In the present review, the STAT/NF- $\mathrm{BB}$ pathway of the cnidarian Nematostella vectensis is compared with that of human tumors (malignant lymphomas, including Reed-Sternberg cells) pointing out similarities, including possible viral initiation in both cases. In the ctenophore genome and proteome, $\beta$-catenin gains intranuclear advantages due to a physiologically weak destructive complex in the cytoplasm, and lack of natural inhibitors (the Dickkopfs). Thus, a scenario similar to what tumor cells initiate and achieve is presented through several constitutive lossof-function type mutations in the destructive complex and in the elimination of inhibitors. Vice versa, malignantly transformed individual cells of advanced multicellular hosts assume pheno-genotypic resemblance to cells of unicellular or early multicellular hosts, and presumably to their ancient predecessors, by returning to the semblance of immortality and to the resumption of the state of high degree of resistance to physicochemical insults. Human leukemogenic and oncogenic pathways are presented for comparisons. The supreme bioengineers RNA/DNA complex encoded both the malignantly transformed immortal cell and the human cerebral cortex. The former generates molecules for the immortality of cellular life in the Universe. The latter invents the inhibitors of the process in order to gain control over it.
\end{abstract}

Correspondence to: Professor Joseph G. Sinkovics, Cancer Institute, St. Joseph's Hospital, 3001 W Dr Martin Luther King Jr Blvd, Tampa, FL 33607-6307, USA

E-mail: sinkovi.joseph@baycare.org

Key words: early metazoans, eukaryotic cells, cell survival pathways, proto-oncogenes, oncogenes, oncoproteins, oncogenesis, malignant lymphoma, Reed-Sternberg cell

\section{Contents}

\author{
1. Introduction \\ 2. The cnidaria class anthozoa \\ 3. The primordial cell survival pathways become \\ proto-oncogenes \\ 4. Ctenophores \\ 5. Discussion \\ 6. Conclusion
}

\section{Introduction}

Of the genes encoding the body plane/axis/design in ontogenesis, and the stress-responses in adult life in the immense numbers of life forms emerging in the Cambrian sea, nuclear factor kappa B $(\mathrm{NF}-\kappa \mathrm{B})$, STAT (signal transduction and transactivation), and $\beta$-catenin-dependent transcriptional activators have gained utmost and ever-lasting prominence. In the cnidarians, Toll-like receptors activated NF- $\kappa \mathrm{B}$ to function as a stress response inducing cell survival pathway. The STATs are co-activators. In the advanced mammalian vertebrate hosts (including Homo), the $\beta$-catenin-based Wnt, and the $\mathrm{NF}-\kappa \mathrm{B} /$ Relp65 pathways have become the principal inflammatory STAT-associated proto-oncogenes/oncoproteins.

In the tunicate urochordate Ciona ( $C$. intestinalis) the Wnt/ $\beta$-catenin pathway regulates body design, first the transspeciation of the swimming larva to the sessile 'intestinal' adult. In the decapitated hydra (H. magnipapillata/viridis), the Wnt/ $\beta$-catenin (with Notch and PI3K) pathways regenerate a new head. In the other cnidarian, Nematostella vectensis (Fig. 1) next to the Wnt pathway, the NF- $\kappa \mathrm{B} / \mathrm{STAT}$ pathway fulfills essential physiological tasks. In the advanced multicellular vertebrate hosts (including Homo), $\beta$-catenin has become one of the most malignant oncoproteins, as it acts for example, in colon carcinogenesis. In Wnt carcinogenesis, the cytoplasmic ' $\beta$-catenin destroying complex' fails to phosphorylate $\beta$-catenin, thus, the complex does not mark it for ubiquitination. Intact accumulating $\beta$-catenin is allowed to translocate from the cytoplasm into the nucleus for the activation of oncoprotein promoter DNAs; primarily that of tcf/TCF and lef/LEF (Fig. 2). Furthermore, the Wnt antagonist Dickkopf tumor suppressor gene is forcefully eliminated. In the human genome, the NF- $\mathrm{B}$ /STAT pathway has assumed the role of a 


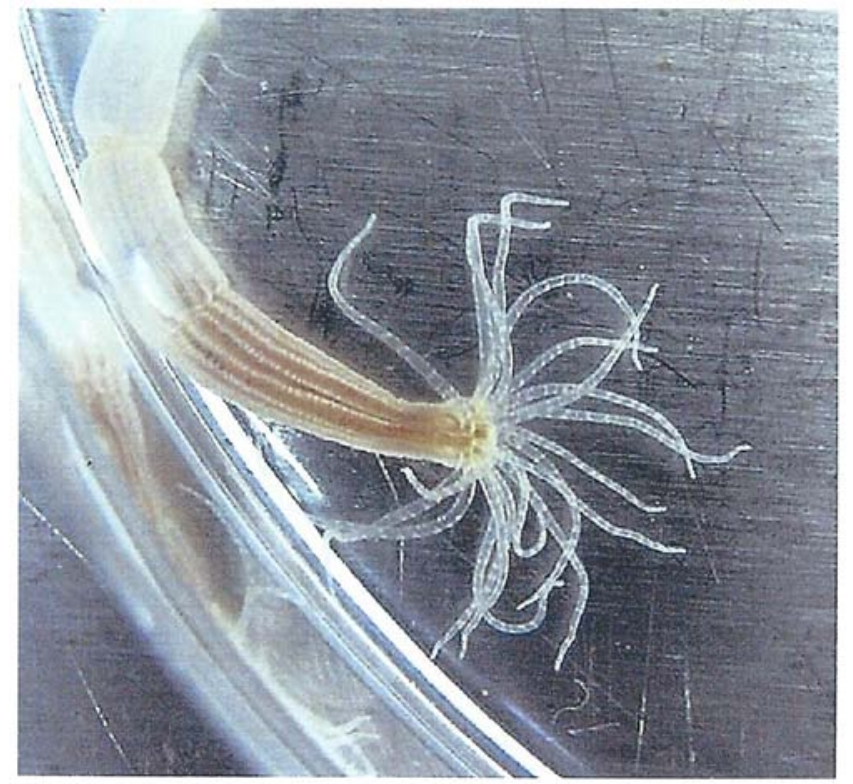

Figure 1. The sea anemone anthozoan cnidarian Nematostella vectensis possesses several ontogenetic and cell survival pathways dominant among them the WNT and NF- $\mathrm{KB} / \mathrm{STAT}$ enzyme-catalyzed sequential reactions $(7,125)$. The copyright holder Creative Commons Attribution-Share Alike 3.0 License granted permission for the reproduction of this document under the terms GNU Free Documentation License.

proto-oncogene. When constitutively activated, it induces B cell malignant lymphomas in the mediastinum and elsewhere. It is highly active in the Reed-Sternberg cells of Hodgkin's lymphoma.

The rapidly expanding comb jelly ctenophores (represented here by Mnemiopsis leidyi) (Fig. 3) operate a physiologically defective cytoplasmic $\beta$-catenin destroying complex promoting $\beta$-catenin's intranuclear transfer for activation of the predecessors of those genes (tcf/lef), which have become proto-oncogenes in the human genome. The ctenophore genomes do not possess ancestral Dickkopf genes, which have become tumor suppressors in the human genome. Furthermore, the ctenophore genome operates a full set of sox/Sox genes/proteins, which sustain pluripotent stem cells through the entire eukaryotic evolution, and may convert into oncogenes in the human genome. The ctenophore genome is a physiological oncogenome.

\section{The cnidaria class anthozoa}

Cell survival pathways. In 2006, it was surprising that the little invertebrate basal animal, the burrowing sea anemone, Nematostella vectensis (Fig. 1), carried an abundance of 'human disease genes' (1). The numbers and positions of the introns in orthologous cnidarian and human genes reveal unusually high concordance in 47 and $69 \%$, respectively, surpassing those of invertebrate insects and nematodes $(2,3)$. Most of these genes are stress responder metabolism regulators $(4,5)$. Prominent among them are oxidative stress-activated receptors and others, the aryl hydrocarbon receptor, AhR; and the hypoxia-inducible factor, HIF. Furthermore, operational are the ligand-activated nuclear receptors, ancestral predecessor of the hepatocyte nuclear factor; retinoic acid receptor (RAR); signal transduction proteins; transcription factors (including $\mathrm{NF}-\kappa \mathrm{B}$, nuclear factor kappa B cell lymphoma); oxidizing, reducing, conjugating enzymes; oxidative cytochrome $\mathrm{P} 450$ enzymes (CYPs); and heat shock proteins (HSP), in several subfamilies. The cyp gene progenitor of animals (not plants) created a tandem set of duplicated genes, which utilized oxygen to modify substrate structures. Plant cells have acquired cyp genes from marine animals by horizontal transfer. Of the animal cyp gene clans, Nematostella possesses up to 46. Cyp genes are absent in the anaerobic Giardia, but are present in the aerobic Saccharomyces. The sponge (Amphimedon) operates 35, the amphioxus (Branchiostoma) has 236 cyp genes. Precursor cyp genes existed interspersed with hox, wnt and arf (homeodomain box; wingless; alternative reading frame GTPases) gene clusters (6). Later in evolution, the P450 genes lying downstream from the AhRs, will assume prominent roles, especially in hormone-dependent molecular carcinogenesis (breast cancer) (vide infra).

There are active efflux pumps in cnidarians operated by 64 ABC genes. The HSP (probably inherited from Archaeoglobus fulgidus) have assumed the evolutionary role of chaperoning oncoproteins in multicellular vertebrate hosts (including Homo). The descendant enzymes of the original ATP-binding cassettes (ABC) present in extant (and presumably ancient extinct) zooxantellae, act as ATP-dependent efflux transporters in pumping out molecular chemotherapeuticals from malignantly transformed (cancer) cells in multicellular vertebrate mammalian (human) hosts (as referenced in 7). Of biotransformators, there are glutathione- and sulfotransferases, but no acetyl transferases. Of antioxidant proteins, there are 6 superoxide dismutase (SOD) genes $(4,5)$.

Virus-carrier algal symbionts. Some cnidarians and paramecia accept the intracellular invasion by chloroplast- and virus-carrier eukaryotic chlorella green algae (Chlorella vulgaris; $C$. variabilis) and live with them in symbiosis (8). In the case of the Florida strain of Hydra virilis (in culture for over 20 years; fed with tiny pieces of brine shrimp), and the chlorella green alga, the symbiotic algal cells taken out from the hydra immediately succumbed to the replication of the Hydra virilis dsDNA chlorella virus 1,2 and 3 (HVCV). The virus proved to be lytic to the algal cells taken from the hydra, but not to the hydra cells. Thin section of hydra cells viewed in transmission electron microscopy failed to show viral particles. These original observations remain cited in the literature of better technology; recent metagenomic studies reveal the widely spread presence of herpes-like viral agents in cnidarians, especially in Porites corals, but also including Hydra and Nematostella. Viral particles invade cells of the hosts and the cells of their symbiotic zoochlorellae and zooxantellae (9). The symbiotic life style and the virology of zooxantella Symbiodinia algae have been discussed (10). Proteobacteria and Bacteriodetes and their phages colonize various species of Hydra. Myoviridae and Podoviridae Burkholderia; Syphoviridae Staphylococcus; and Herpesviridae and Phycodnaviridae make up the microbiome flora of the holobiont (11).

The genomes of Hydra magnipapillata and Nematostella vectensis do not tolerate these symbiotic relationships, thus, reject the potential symbionts $(10,11)$. Maltose-producing 


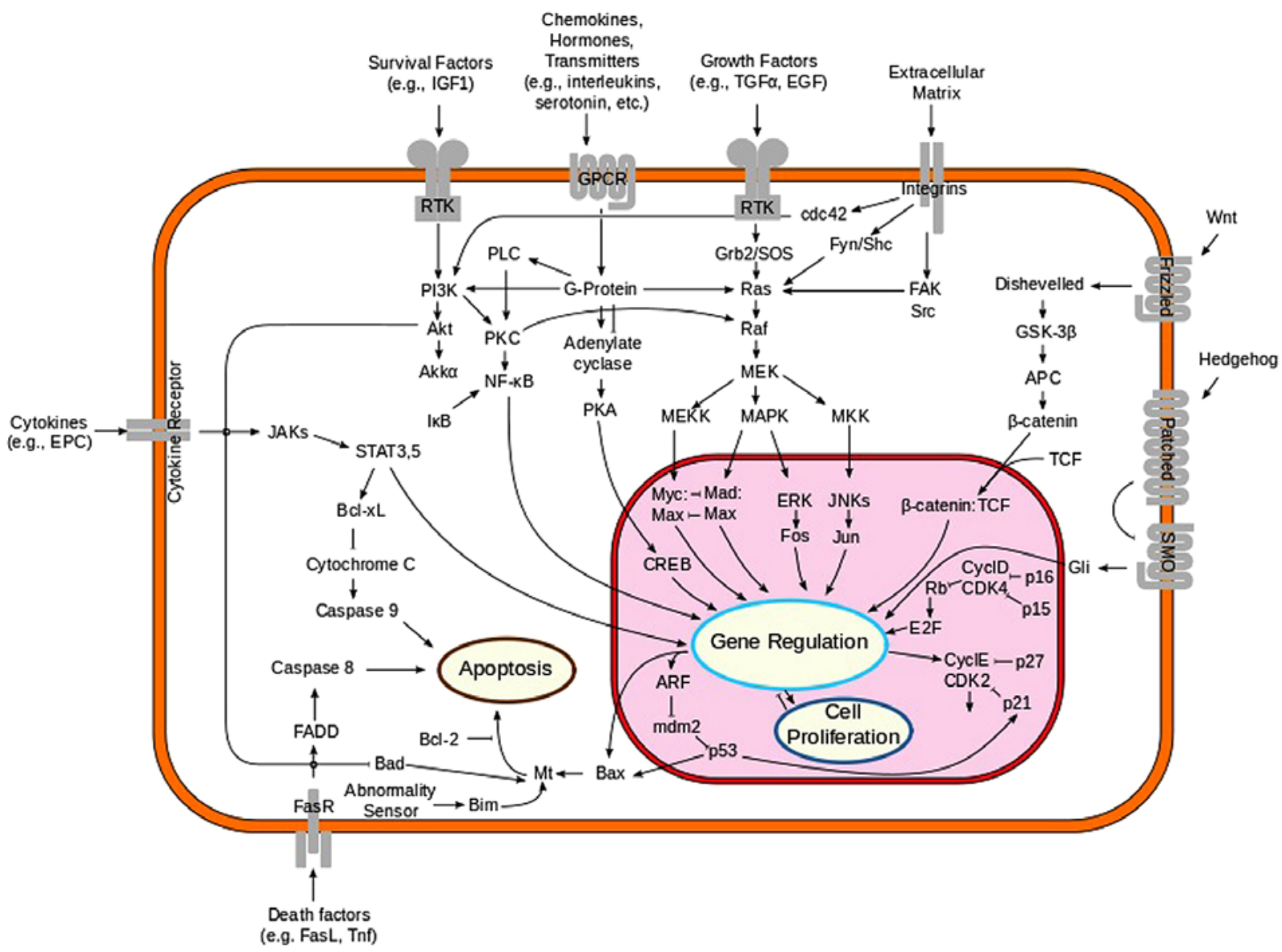

Figure 2. A collection of pathways operational in the human genome/proteome, which have taken their origins in primordial unicellular and early multicellular organisms. The WNT/ $\beta$-catenin pathway shown in the right upper corner and the NF- $\mathrm{B} / \mathrm{STAT}$ pathway in the left upper corner is very active in the cnidarians and ctenophores, respectively. Both pathways physiological at the time of their ancestry, but function as transforming proto-oncogenes in the human genome. Other pathways are referred to in the Text. The copyright holder Creative Common Attribution-Share Alike 3.0 Unported licence granted permission for the reproduction of this document under the terms GNU Free Documentation License.

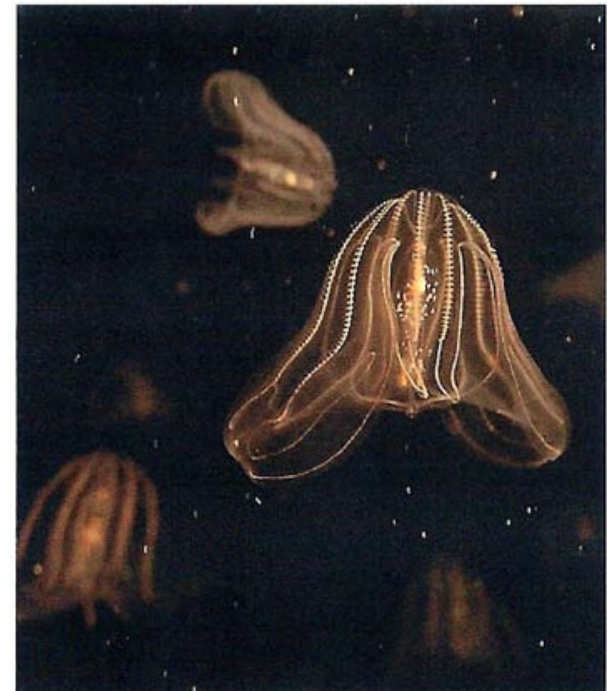

Figure 3. The ctenophore sea walnut Mnemiopsis leidyi from the New England Aquarium, Boston, MA, by Steven G. Johnson. Wikimedia Commons freely licensed media file repository. Creative Common Attribution Share Alike 3.0 License. GNU Free Documentation License Version 1.2. The ctenophore genome's WNT pathway is physiologically defective in that, its cytoplasmic ' $\beta$-catenin destructive pathway' allows the transfer of $\beta$-catenin into the nucleus for the activation of the promoters of cell cycle-dependent kinase genes, and lacks their natural inhibitors Dickkopf, that are to be acquired later in evolution. algae gained protection against cnidarian host cell lysosomes. Intolerant (symbiosis-free) host cells mobilized the ancient MAMP-PRR interaction (microbe-associated molecular pattern; pattern recognition receptor) (10). In this interaction, host cells release lectins that bind cell surface glycans (galactose; mannose) of the invaders.

Proto-oncogene predecessor $N F-\kappa B$. The activation of $\mathrm{NF}-\kappa \mathrm{B}$ is ancestrally TLR Toll-like receptors-mediated (4). By its RHD (reticuloendothelial viral antigen homology domain), the two alleles Nv-NF- $\kappa \mathrm{B}$ proteins bind their target-DNA. The consensus sequence of the DNA recognition loop has either cysteine or serine at position 6 , and the serine variants are the more potent activators. All other (including human) 440 aa $\mathrm{NF}-\kappa \mathrm{B}$ proteins have cysteine in position six in the consensus (except for one of Drosophila's four RHD proteins; there, the Relish RHD has serine). The choanoflagellates (Monosiga) do not encode RHD proteins, but the Amphimedon demosponge possesses one, thus, predating the appearance of numerous RHDs after the triploblast divergence. The human genome encodes twenty RHD proteins. Some human RHD proteins may also undergo a Cys-to-Ser mutation $(12,13)$. Both in the cnidarian and in the human RHD, serine in position six results in increased transactivational potency. It would be interesting 
to know, if resting cells operate cysteins, vs. constitutively activated cells (including the so-called malignantly transformed cells), serins, in the DNA recognizing consensus loops of their NF- $\kappa B$ RHDs. Ancestral ADAM (A disintegrin and metalloproteinase) exists in cnidarians; STATs, TNF $\alpha$ (tumor necrosis factor), and its signaling proteins, SOD and anti-apoptotic Bcl-proteins (B-cell lymphoma), are functional as well. In the human genome encoding the mantle cell lymphoma, it will be ADAM that activates the TNF $\alpha / \mathrm{NF}-\kappa \mathrm{B}$ pathway (14) (vide infra). Promoters of intranuclear translocation of $\mathrm{NF}-\mathrm{\kappa B}$ are interleukin IL-1, $\mathrm{Ca}^{++}$-ionophore, PMA (phorbol myristate acetate) and TNF $\alpha$. NF- $\kappa B$-inducing kinase (NIK) and the inhibitor of apoptosis (IAP) are antagonistic to each other (15-17). The cytoplasmic IкB kinase phosphorylates $\mathrm{I} \kappa \mathrm{B} \alpha$, thus initiating its ubiquitination, that leads to the release of NF- $\kappa B$. The dominant form of the NF- $\kappa B$ family is its p50/p65 heterodimer, which is acetylated. Deacetylase inhibitors (trichostatin) initiate and potentiate the activation of $\mathrm{NF}-\kappa \mathrm{B}$ by $\mathrm{TNF} \alpha$, including its intranuclear entry and attachment to its numerous pro-inflammatory DNA targets. Among the NF- $\kappa \mathrm{B}$ targets is the gene of its own inhibitor $\mathrm{I} \kappa \mathrm{B} \alpha$. The cytoplasmic IкB $\alpha$ gene-product protein enters the nucleus, binds the NF- $\kappa B$ proteins and leads them back neutralized into the cytoplasm. Deacetylase inhibitors delay this process and thus increase NF- $\kappa B$ activity. After its release from its cytoplasmic inhibitor I $\kappa \mathrm{B}$, the intranuclear translocation and mobility of the NF- $\mathrm{kB} / \mathrm{p} 50 / \mathrm{p} 65$ heterodimer is dependent on the acetylation of five of its lysins; four of these residues contact the targeted DNA domains. The transcriptional activity of the NF- $\kappa B$ p65 subunit is further regulated by phosphorylation of its various serine residues $(18,19)$.

The Nematostella operates at least one STAT pathway in co-existence with NF- $\mathrm{KB}(20,21)$. The origins of the 553 pathway date back to the ancestors of choanoflagellates and cnidarians (N. vectensis) $(22,23)$. However, the ancestral and extant choanoflagellate, cnidarian and Spongiae genomes operate without an MDM (murine double minute) pathway (24). The first signs of MDM protein appear in the placozoan Trichoplax adhaerens and in the sea squirt $C$. intestinalis (25). Since the placozoan T. adhaerens possesses the anti-apoptotic MDM protein (25), presumably cnidarians ( $N$. vectensis) also have it, but no proof was found (23). Choanoflagellates (Monosiga) and spongiae (Amphimedon) are devoid of mdm/MDM possessions (24).

Cnidaria-related proto-oncogene $N F-\kappa B / S T A T$ in the human genome. NF- $\kappa \mathrm{B}$ is TCR/TNF $\alpha$ - (T cell receptor), IL-1 $\beta-$, or mitochondrial stress-induced; calcineurin forces the release of NF-кB from inhibitor ІкB $(26,27)$.

In the cellular transformation process, loss-of-functionmutated $i \kappa b \alpha / \mathrm{I} \kappa \mathrm{B} \alpha$ (inhibitory/inducing kappaB kinase) permanently releases the NF- $\mathrm{KB}$ molecule. In Reed-Sternberg (RS) cells of Hodgkin's lymphoma, among others, the constitutively activated NF- $\kappa \mathrm{B}$ gene/protein targets the promoter DNAs of STAT5a, chemokine receptor CCR7, cyclin D2, and inhibitors of apoptosis c-IAP2 and Bcl-xL (B cell lymphoma extra large). Interleukins (IL-13 and IL-15), macrophagederived chemokines, and cytokines induced by NF- $\mathrm{kB}$ in the RS cells invoke the extraordinary cellular infiltrates which surround the RS cells (28). In the human lymphoma cell line
YT, STAT3 and STAT5 are the promoters of the malignant transformation; the tyrosine- and serine-phosphorylated STAT3 is constitutively activated, but both STATs are antiapoptotic. Neither the jak1, 2, 3/JAK (Janus kinase), nor IL-2 are drivers of STAT3, even though STAT3 expresses domains for IL-2 binding. Antisense STAT3 and STAT5 blockade induced apoptosis. IL-2 could rescue the lymphoma cells from apoptotic death consequential of STAT3 blockade, but not in case of STAT5 blockade. STAT5 depletion resulted in reduced NF- $\mathrm{KB}$ and TNF $\alpha$ activity. Helenalin, the inhibitor of DNA-binding by NF- $\kappa \mathrm{B}$, induced lymphoma YT cell death. The YT lymphoma cells resisted the blockade of the IL-2induced pathways MAPK, PI3K, mTOR (mitogen activated protein kinase; phosphatidyl inositol kinase 3; mammalian target of rapamycin) (29). Common promoters of NF- $\kappa \mathrm{B}-$ induced diffuse large B-cell lymphomagenesis are the $\mathrm{B}$ cell activation factor (BAF), constitutively expressed B-lymphocyte stimulator (BLyS), autochthonous B-lymphocyte stimulator ligand, and the NF- $\kappa \mathrm{B}$-inducing kinase, accompanied by the degradation of the TNF-R-associated factor $(30,31)$. The EZH2-mediated (enhancer zeste homolog histone 3 lysine methyltransferase, Drosophila), hotspot-mutated, NF-кBinduced, mediastinal diffuse large B cell lymphomas are rare, but highly malignant (32).

In human lymphoid cells undergoing malignant transformation (RS cells of Hodgkin's disease, mediastinal diffuse large B cell malignant lymphoma, certainly; mucosa-associated lymphoid tissue MALT lymphoma, multiple myeloma, mycosis fungoides, probably), the classical NF- $\kappa$ B pathway undergoes amplification, or gain-of-function mutation, resulting in constitutive expression of the molecule. NF- $\mathrm{KB}$ remains frequently co-activated with STATs. In these entities, amplification of the NF- $\mathrm{kB}$ pathway is encoded by the Rel locus at 2p14-15 (reticuloendotheliosis viral oncogene homolog). $\mathrm{TNF} \alpha$ phosphorylates serine Ser-471 in c-Rel for the activa-

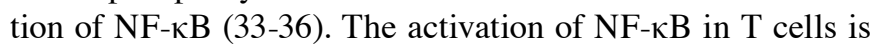
initiated by p65/RelA through triggering TCR/CD3 (cluster of differentiation) and completed by $\mathrm{TNF} \alpha$, secreted either autocrine or paracrine. TNF $\alpha$ induces the degradation of IкB kinase and activates the wild-type c-Rel by phosphorylation of its Ser-471. This stimulation of TNF $\alpha$ to activate NF- $\mathrm{KB}$ cannot occur in Burkitt's lymphoma $\mathrm{T}$ cell lines (Jurkat) with mutated Ser-471 (S471N, asparagine replacing serine) (15). In diffuse large B-cell lymphoma, NF- $\kappa \mathrm{B}$ is constitutively activated by an NF- $\mathrm{KB}$-inducing kinase; in addition, BAF is also constitutively expressed (but no attention was turned toward STAT) (37).

Furthermore, translocations and fusions of NIK (NF- $\mathrm{kB}-$ inducing kinase) and NF- $\kappa \mathrm{B} 1$, two genes and gene-product proteins occur with the involvement of apoptosis inhibitor IAP (another hallmark of malignant transformation) $(16,17)$. In evolutionarily more advanced cells (taken from mice or humans), mitochondria-to-nucleus stress-signaling activates NF- $\kappa B /$ Rel. Calcineurin-mediated inactivation by dephos-

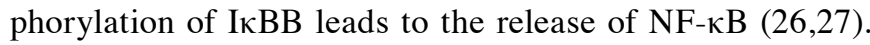
However, the metazoan mitochondria had the time to develop genetic variations after the divergence of advanced triploblastic metazoa from the ancestral lineage of cnidarians $(38,39)$. In the cytoplasm, the IкB/NF- $\kappa \mathrm{B}$ complex is heat-labile and can be disrupted by HSP, thus, liberating NF- $\mathrm{kB}$. In the nucleus, 
$\mathrm{NF}-\kappa \mathrm{B}$ can target and induce the transcription of the I $\kappa \mathrm{B}$-genes (among others). The newly synthesized $\mathrm{I} \kappa \mathrm{B}$ protein can bind intranuclear DNA-bound NF- $\kappa \mathrm{B}$, and remove it from its bond. Exportin proteins return $\mathrm{NF}-\kappa \mathrm{B}$ from nucleus to cytoplasm. This interplay was observed in HIV-1-infected cells, and in HeLa cells (40). The Rel protein (reticuloendothelial viral antigen) homology domain (RHD) of NvNF- $\mathrm{KB}$ is $50 \%$ identical with the human p50/p52 Rel homology domain (RHD) proteins. Both the cnidarian and the human NF- $\kappa \mathrm{B}$ proteins interact with the Bcl-3 (B cell lymphoma; cell cycle; antiapoptosis) and c-Myc proteins $(12,13)$ (vide infra).

The ancient combined TNF $\alpha$, STAT and NF- $\kappa$ B pathways recur in the pathogenesis of human malignant lymphoma. Phosphorylation of human cytoplasmic inhibitory I $\mathrm{B}$ releases $N F-\kappa B$ for its intranuclear transfer. In the nucleus, the $\mathrm{NF}-\kappa \mathrm{B} / \mathrm{RHD}$ complex activates directly or indirectly some of its 140 DNA targets, including proinflammatory interleukins (IL-1, -2 and -6). Point-mutated codon S525P serine to proline human rel/REL oncogene/oncoprotein is active in human mediastinal B cell lymphoma. The mutated REL protein transactivates the manganese SOD promoter and renders transformed cells resistant to TNF $\alpha$-induced apoptosis (41).

The promoter of miR-155 expresses NF- $\kappa \mathrm{B}$-responsive sites (42). Physiologically, miR-155 positively regulates the immune response of $\mathrm{CD}^{+} \mathrm{T}$ cells (43). The promoter of the human pro-inflammatory microRNA-155 cluster carries a $\mathrm{NF}-\kappa \mathrm{B}$ p 50/p65 responsive site. The miR-155 promoter is a target gene for the NF- $\kappa \mathrm{B}$ protein. Activation of $\mathrm{miR}-155$ (by $\mathrm{NF}-\kappa \mathrm{B}$ ) is essential for optimal $\mathrm{CD}^{+}$immune response $(42,43)$. In the human cutaneous $\mathrm{T}$ cell lymphoma mycosis fungoides, miR-155 suppresses STAT4 expression by targeting its mRNA for its neutralization, and thus canceling the Th1 phenotype of the host; in the opponent established STAT6/Th2 environment, tumor growth prevailed. The Janus kinases JAK1 and 3 activate and sustain different STAT3, 5 levels (44). The miR-155 is a driver of the aggressive folliculotropic mycosis fungoides (45).

$N F-\kappa B / S T A T / P I 3 K$ proto-oncogenes in virus-carrier human cells. In the human genome the $\mathrm{NF}-\kappa \mathrm{B} / \mathrm{STAT}$ association is prominently active in infectious processes, and in the malignant transformation of selected cells. STAT4 and NF- $\kappa$ B (p65) were expressed highly in tuberculoid leprosy, according to immune reactions induced by interferon- $\gamma(46) . N$. vectensis is not known to possess IFN $\gamma$ (3), but as a predecessor of the system to come, it expresses alternatively spliced mRNAs to bind tRNAs and GAIT element RNAs (interferon- $\gamma$-activated inhibitor of translation) (47).

As a distant upward derivative of the viral-carrier $N$. vectensis genome (vide supra), retrovirally and herpesvirally infected human mesenchymal cells frequently express NF- $\kappa$ B/STAT/PI3K (phosphatidyl inositol kinase) co-existing pathways, often constitutively and in cells malignantly transformed. In RS cells, STATs and NF- $\kappa \mathrm{B}$ co-exist. STATs act in antagonistic terms: STAT6 anti-, and STAT1 pro-apoptotically. RS cells operate constitutively activated JAK/STAT pathways; the DNA-binding STAT proteins entering from the cytoplasm to the nucleus, activate their targets for the malignant transformation of the cell (here, not by the stimulation of the cell cycle, since RS cells are known for long periods of rest) $(48,49)$. It is the gene bcl-3 (B-cell lymphoma) at chromosome $19 \mathrm{q} 13$,

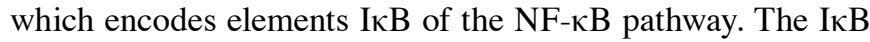
molecules form complexes with the five NF- $\kappa \mathrm{B} / \mathrm{Rel}$ family member proteins in the cytoplasm. Degraded $\mathrm{I} \kappa \mathrm{B}$ molecules release $\mathrm{NF}-\kappa \mathrm{B}$ proteins for their translocation into the nucleus, in order to accomplish their DNA-bindings. Aberrant Bcl-3 protein constitutively releases an excess of $\mathrm{NF}-\kappa \mathrm{B}$ proteins for intranuclear transfer, where they bind the promoters of their target genes, which encode chemokines, cytokines and their receptors; anti-apoptotic molecules and various transcription factors, including persistently activated STATs (50). Viral DNA (herpesviral, HHV4, HHV6 and HHV8) (51-55), and RNA (retroviral, HIV; HTLV-I) (56) infections can force the cytoplasmic I $\mathrm{B}$ inhibitors for the release of $\mathrm{NF}-\kappa \mathrm{B}$ molecules. In particular, open reading frame ORF-1 (referred to as disease-related DR7) of the extant HHV6 encodes a p53-binding protein, which renders it anti-apoptotic. In RS cells, DR7B is an oncoprotein; it downregulates p53 and activates $\mathrm{NF}-\kappa \mathrm{B}$ (54). The herpesvirus-carrier $N$. vectensis does not operate a pro-apoptotic p53, but has its ancestral predecessors, p63/p73 (23). In the human genome, p53 eliminates mutated cells by apoptosis. In the process of malignant transformation, it is acting as a tumor suppressor gene, unless, the cell eliminates the MDM-bound p53 protein by ubiquitination (vide supra).

The genomes of herpesvirally infected human cells (HHV4, EBV; HHV8, KSHV) readily respond with NF- $\kappa$ B/STAT activation $(51,52,55,56)$. Human malignant cells transformed by circular dsDNA papillomaviral genomes resist apoptosis, gain immortality (the HeLa cells), and chemo-radiation resistance (58). Could the DNA virom-carrier Hydra and Nematostella cells (8) be driven by constitutively activated NF- $\mathrm{B} / \mathrm{STAT}$ pathways, thus, resembling cells in the process of malignant transformation higher up on the evolutionary scale?

$N F-\kappa B / S T A T$-inhibitors. Dexamethasone, pyrrolidine dithiocarbamate, BAY-11-7082; the sponge-derivative marine natural product microsclerodermin inhibit or alter the excretions of inflammatory chemokines (CXCL8/10) and interleukins (IL-1 $\beta$, IL-6 and IL-8), but have not been enlisted as effective anticancer agents (59-61). Anti-NF- $\kappa$ B RNA-aptamers (specifically target-binding short ss nucleotides) and siRNAs are powerful NF- $\kappa \mathrm{B}$ inhibitors (62), not yet in clinical use. In gram-negative septic shock, lipopolysaccharide endotoxins degrade $\mathrm{I} \kappa \mathrm{B} \beta$ and liberate $\mathrm{NF}-\kappa \mathrm{B}$, which may induce an interleukin (IL-1 $\beta$, IL-6 and IL-12 $\beta$ ) storm (63). In grampositive septic shock lipoteichoic acid LTA, activates toll-like receptor TLR2, which induces the proto-oncogene cascade of Raf/MEK/ERK/NF- $\kappa$ B. LTA promotes the transfer of $\mathrm{NF}-\kappa \mathrm{B}$ from cytoplasm to nuclei; this is inhibited by propofol (64).

The sesquiterpene lactone parthenolide inhibits NF- $\kappa \mathrm{B}$ by alkylating p65 at Cys (65). Synthetic epoxyquinone A monomer is a potent inhibitor of $\mathrm{NF}-\kappa \mathrm{B}$ resulting in the cessation of growth of human lymphoma cells $(66,67)$. The $\mathrm{NF}-\kappa \mathrm{B}$ inhibitor parthenolide induced apoptotic death of p31 ras- and PI3K/Akt-driven malignantly transformed cells (rat sarcoma oncogene; phosphatidylinositol-3 kinase; AK mouse thymic lymphoma retroviral oncogene). This effect was mediated by downregulation of the inhibitor of apoptosis IAP2, and degradation of polyadenosine-diphosphate-ribosyl- 
transferase (PARP). In p210 BCR/ABL-transformed cells (breakpoint cluster region; Abelson mouse retroviral oncogene), parthenolide treatment failed to induce apoptotic deaths due to antagonism by STAT5 and BCL-xL activation (B cell lymphoma extra large) (32). Under natural circumstances (in the cell) siRNA and RNA aptamers (specific target-binding nucleotide or peptide biomolecules) disable NF- $\mathrm{kB}$ mRNAs. In the RNA-induced silencing complex (RISC), helicases unwind the dsRNA molecules, thus, the antisense RNA strand can align with the receptive UTR (untranslated) domain of the mRNA strand and neutralize it (62). In contrast, O-linked $\mathrm{N}$-acetyglucosamine by glycolysation (oligosaccharide; $\mathrm{N}$-terminal) post-translationally activates the NF- $\mathrm{\kappa B}$ molecule by acylating its serine 350 . Interacting are TCR and TNF $\alpha$ in encoding NF- $\kappa \mathrm{B}$ target gene I $\kappa \mathrm{B} \alpha$. TCR and TNF $\alpha$ may activate NF- $\kappa \mathrm{B}$ with or without O-GlcNAcylation (OGT, O-linked GlcNAc transferase; N-glucoseamine acetyl) (68). The Cys-to-Ser mutated human NF- $\kappa$ B RHDs are not only gaining translational activity, they become resistant to their natural inhibitors sesquiterpenes and possibly to curcumins (vide supra). The post-translationally functioning nucleocytoplasmic protein for O-GlcNAcylation first appeared in prokaryota, and remained functional in the low-branching Giardia and in the placozoan Trichoplax adhaerens (69), cultured and fed by red alga Rhodomonas salina. The ancient system O-GlcNAcylation was discovered in the Drosophila (70), but it must have been present at the beginning of cellular life and remains active in every cell. It is overexpressed in mitotic cells. Further physiological blockade of NF- $\kappa B$ is brought about by the $\mathrm{p} 53$-neutralizing protein, ubiquitin ligase MDM2 directed at p65Rel (71).

Helicobacter pylori activates in gastric epithelial cells the expression of IL-8, Jak1/STAT and NF- $\kappa$ B (72). In the targeted cells several ligands bind their receptors, as shown in Fig. 1 of the cited article (20). The physiological inhibitor of the Jak/STAT pathways is SOCS (suppressor of cytokine signaling). The ancestral Jak proteins appear in the choanoflagellates (C. owczarzaki), and the STAT proteins in the cnidarians and sponges (Nematostella vectensis; Amphimedon queenslandica). The ankyrin repeats and the SH2 domains (Src homologues, after Rous sarcoma virus) of the archetypical SOCS also appear early in the cnidarians (N. vectensis) (20). Inhibition of the STAT3/5 pathways in human breast cancer cells in vitro was accomplished through siRNA-mediated knock-down of the gene SLC7A11, also known ASCT (alanine, serine, cysteine transporter, $\mathrm{xCT}$ and solute carrier family 7). It protected the cells from stress by reactive oxygen species (73). Capsaicin was found to inhibit disheveled in the Wnt pathway of human pancreatic carcinoma cells. Consequentially, GSK (glycogen synthase kinase) was not phosphorylated and the APC/Axin complex (adenomatosis polyposis coli) was activated. Unphosphorylated cytoplasmic $\beta$-catenin was degraded in the proteosome. Intranuclear $\beta$-catenin target genes tcf/TCF, c-myc/Myc, cyclin D and STAT3 were not activated; cytoplasmic STAT3 protein was not phosphorylated at Tyr705. Capsaicin-treated pancreatic carcinoma cells undergo caspase-3 cleavage and die in apoptosis. Antagonistically, IL-6 activated STAT3 (p-STAT-3 Tyr705), and increased intranuclear $\beta$-catenin levels. Lithium chloride by inhibiting GSK, saves $\beta$-catenin from phosphorylation and thus degradation; it is ready for intranuclear transfer. Orally administered capsaicin reduced the growth rate of orthotopic human pancreatic cancer xenografts in athymic nude mice. These tumors showed low $\beta$-catenin, TCF and p-STAT3 levels, and increased cleaved caspase-3 levels leading to their apoptosis (74).

Autophagy. Under stress, Saccharomyceta and Dictyostelia assume an autophagic stage of existence. Autophagy has become an evolutionarily conserved process extended to every eukaryotic species. Its potential reversal indicates that autophagy is not a self-destructive process, but it is a homeostatic phase in cellular life (75). Mitochondrial autophagy (mitophagy) (76) indicates that the origin of the process predated the appearance eukaryotes. The wild hydra may live in a steady stage of autophagy and eventually recover. The mTOR inhibitor rapamycin induces, wortmannin and bafilomycin inhibit autophagy. In the hydra during starvation for weeks, myoepithelial cells form autophagic vacuoles. Endodermal digestive cells with knocked-out Kazal gene (serine peptidase inhibitor Kazal, SPINK, vide infra) die, whereas ectodermal epithelial cells survive in autophagy (77,78). Break-down of the symbiotic relationship between host cnidarian and symbiont dinoflagellate alga leads to autophagy and apoptotic death of the host. Drastic environmental changes (temperature; ultraviolet light; reactive oxygen species, ROS; loss of antioxidant defenses; water $\mathrm{pH}$ changes; microbial invaders; combination of unknown factors) induce the process. The process could be induced by the TOR inhibitor rapamycin (target of rapamycin). Hyperthermic-stressed (HTS) anemones released larger number of symbionts than subjects kept on termed control temperature (CT); however, exposure to rapamycin induced symbiont release in CT anemones. It was either autophagy or apoptosis that dominated, and possibly sphingosine kinase and PI3K signaling regulated a see-saw relationship between the two outcomes (79). Alloreactivity after transitory fusion of hydractinia ( $H$. symbiolongicarpus) colonies with minor incompatibilities is another cause of irreversible autophagy terminating not in apoptosis, but in necrosis (observe electron microscopic pictures in the cited article) (80).

The Wnt pathway remains dominant for the regeneration of a new head in the decapitated hydra (81). The enzyme Kazal (vide supra) in the hydra prevents autophagy and promotes selfpreservation; after amputation, it encodes de-differentiation and transdifferentiation, blastemal transition, and activates the ontogenic organizer pathways, for example those of the head regeneration. View color pictures of Hydra proteomics (metalloproteinases, thrombospondin, tubulin network, mitochondria, and Kazal type 1 enzyme expression: its disappearance in autophagic cells after its dsRNA knock-out (by feeding), and its reappearance during regeneration. This study shows that the hydra Kazal(-) phenotype mimics autophagic mammalian pancreatic cells with non-functional trypsinogeninhibitor SPINK1/3 (citing the literature on the mouse experiments). The pancreas upregulates SPINK3 expression in the gland regenerating after injury (82-84). The ancient serine protease inhibitor (SPINK, Kazal type 1) reappears in the fluid contents aspirated from human pancreatic cysts; these aspirates are analyzed for carcinoembryonic antigens CEA and CA 19-9, but it is the high SPINK content that indicates the 
presence of malignant transformation (it is to be differentiated from chronic pancreatitis by biopsy) (85). The Kazal type 1 serine protease inhibitor SPINK1 gene is subject to pointmutations N34S and P55S (asparagine, proline and serine) in patients with chronic pancreatitis, but not in healthy controls (86). The SPINK1 N34S mutation is considered to be a high risk factor for cancer, especially when increased numbers of pancreatic stellate cells (PSC) co-exist; PSC release proliferation and colony formation inducing molecular mediators to the parenchymal or ductal cells (87).

\section{The primordial cell survival pathways become proto- oncogenes}

Proto-oncogenes ascend to the human genome. In the human genome, all these cnidarian genes and gene-product proteins can function as proto-oncogenes, oncoproteins.

SPARC. The primordial SPARC glycoproteins (secreted protein acidic rich in cystein) forms the mesoglea in between the ectoderm and endoderm of the diploblast cnidarians. In $N$. vectensis, the $\mathrm{Ca}^{++}$-binding glutamic acid-rich acidic domain at its $\mathrm{N}$ terminus is absent. Even in the absence of frank mesenchyme, $N$. vectensis operates the primordial winged helix transcription factor forkhead/and zink finger transcription factor snail gene-product proteins. Snail formats the endodermal cells from invaginating ectodermal cells (88). The $N$. vectensis larva practices the evolutionarily conserved epithelial-to-mesenchymal transition (89). SPARC proteins in advanced multicellular vertebrate eukaryotes (including human cells) are encoded by the genes snail and act as major contributors to epithelial-to-mesenchymal transition of invasive cancer cells-in-locomotion; co-activated are the ligands and receptors of TGF $\beta$ and ERK kinase (extracellular signalregulated kinase), while miR-29b acts as an inhibitor of the process (90). Prominent examples are non-small cell lung cancer and pancreatic and breast cancers expressing melanoma antigen MAGE (91-93).

$R U N X$. The runt-related Runx transcriptional regulatory factors bind the CAAT box (Runx/core binding factor CBF $\beta$ genes) which appeared even before the cnidarians and sponges and continued to evolve in triploblasts and bilateralia. In the figures of the cited article (94), the ancestral eukaryotic protists appearing first 987 mya are compared with the cnidarians (Anthozoa and Hydrozoa) and sponges (Porifera), appearing first 867 mya. The study presents the genes as boxes connected with introns as lines and gives the exon-products in amino acid numbers. These are 35-284 for the Nematostella and 35-219 for the Hydra. Depictions of the groucho-binding motif and the runt domain (RD) are given. Nucleotides 56-434 are shown with digoxygenin labeling. DNA and protein bindings are shown in three dimensions. The $\mathrm{NvCBF} \beta$ protein is in $59 \%$ identical and in $79 \%$ similar to the $\mathrm{HsCBF} \beta$ protein. The sponge $\mathrm{AqCBF} \beta$ protein in $54 \%$ identical with the $\mathrm{HsCBF} \beta$, and in $47 \%$ identical with the NcCBF $\beta$ proteins. As 'packages of stem cells', cnidarians and sponges are able to regenerate from single cells of adult hosts (the archaeocytes of the sponges), including the regeneration of the nerve cells (94). (Further referenced in 7).
The ancestral Runx-CBF $\beta$-DNA complex remained evolutionarily conserved in advanced vertebrate hosts including Homo. In the human genome, runx/RUNX may promote, induce, or obliterate target genes as a multifunctional transcription factor. The expression of FoxP3 in Treg cells is susceptible to suppression by the Runxl/CBF $\beta$ transcription complex (95). In the human host, CBF-leukemias arise due to inv(16) (p13.1q22) or $\mathrm{t}(8 ; 21)(\mathrm{q} 22 ; \mathrm{q} 22)$ involving the NF- $\mathrm{B}$ family kit (tyrosine kinase receptor) gene (96). The Runxl gene (of the Runx family Runx1, 2, 3, same as AML1, acute myelogenous leukemia) forms fusion product with $\mathrm{CBF} \beta$. Further fusion of the amino terminus of AML1 with MLL (mixed linkage leukemias), carrier of histone methyltransferase activity at its C-terminus, SET (suppressor of variegation, Su/var; enhancer of zeste; trithorax, Drosophila) maintains lysine 4 (K) trimethylation of histone $3(\mathrm{H} 3 \mathrm{~K} 4 \mathrm{me} 3)$ in the AML1 target gene PU1 (same as Spi, spleen focus-forming retrovirus proviral integration oncogene). The ternary complex consisting of RUNX1/AML1, CBF $\beta$ and MLL regulates hematopoiesis, but when mutated and constitutively expressed, it induces leukemogenesis (AML or B-ALL) (97). The fusion oncoprotein EWS/FLI1 t(11;p22)(q24;q12) (Ewing's sarcoma; Fos-like immunoreactivity; Finkel osteosarcoma retroviral oncogene; Friend leukemia insertion; here: Friend leukemia insertion at 11q24.3) binds RUNX2 and prevents its action. Runx3 protein promoted oncoprotein EWS/FLI-stimulated target gene responses, and Runx2 and transcriptional co-activator core binding factor- $\beta(\mathrm{CBF} \beta)$ promote invasiveness (98). Runx2 and bone morphogenetic protein (BMP, member of TGF $\beta$ family) upregulated snail-induced lung cancer cell migration and epithelial-to-mesenchymal transition (99). The RUNX3 promoter in inv(16)(p13.1q22) acute myelogenous and lymphocytic leukemias (AML; ALL) is hypermethylated with adverse prognosis. In contrast, non-inv(16)(p13.1q22) and not hypermethylated leukemic patients experienced relapse-free survival. Demethylator decitabine restored RUNX3 mRNA and protein levels with expectation of improved prognosis (100). In the human embryo, the runx/Runx proteins work in hematopoiesis (R1), osteogenesis (R2) and neurogenesis (R3). Gene/protein runx2/RUNX2 is very active in embryonic life in regulating endochondral ossification. Metastatic osteosarcoma with amplified region 6p12-p27, the locus of runx2, remains a lethal tumor; this locus operates two promoters, which constitutively release high mRNA levels of the large DNA-binding protein RUNX2. Directly and by cascading targeted major genes are IGF, BMP, PI3K/Akt, TCF/LEF, FGF, iHh, Wnt (insulin-like growth factor; bone morphogenetic protein; phosphatidyl inositol kinase 3; AK mouse thymus retroviral oncogene; T-cell factor, lymphoid enhancer-binding factor, fibroblast growth factor, Indian hedgehog, wingless/integrated). Suppressed are CDKwaf/cip; and p53 by MDM (cycline-dependent kinase; wild-type p53-activated fragment; cycline-dependent kinase interacting protein; murine double minute protein) (101). Osteosarcoma tumors readily outgrow standard chemotherapy of high dose methotrexate with leucovorine rescue; doxorubicin and ifosfamide; cisplatin. A STAT3 molecular inhibitor (S31-201) inhibited growth, and induced apoptosis of human osteosarcoma cell lines (102). The licensed multikinase inhibitor sorafenib in reduced dosage in combination with cisplatin suppressed phosphorylation of 
extracellular signal-regulated kinase ERK, thus, inhibiting the growth and inducing apoptosis of human osteosarcoma cell lines (103) (see comments in Discussion). The fact that patients with chondro- and osteosarcomas generate immune T- and NK cell-mediated attacks on autologous osteosarcoma cells (104) raises high expectations that CAR cell (chimeric antigen receptor), and checkpoint inhibitor (PD-1/PD-1L) therapy might induce clinical remissions, especially when the tumor cells express NY-ESO antigens (105).

Hedgehog. The first Hog domain proteins appeared in dinoflagellate algae. The hedgehog ( $\mathrm{Hh})$, notch, sox and Wnt genomic pathways operational in the cnidarians remained highly conserved by the triploblastic bilaterians up to vertebrate mammalians (including Homo). The Nematostella $\mathrm{Hh}$ orthologs are among other cnidarian precursors (Wnt, TGF $\beta /$ BMP and FGF) of bilaterian genomic pathways. Here, the Hh ligand-receptor patched (Ptc) represses smoothened (Smo), the inhibitor of Gli (glioma). Capturing the ligand by Ptc, releases Smo, that liberates Gli (glioma-associated oncogene homolog 1). The Nematostella genome contains six genes encodig Hh ligands and receptors, and genes coordinating Wnt, Hh, TGF $\beta$ and FGF (106-108). The role of sensory cilia in Hh signaling emerged in the sea urchin (Strongylocentrotus) and was conserved up to vertebrates. The kinesin motor proteins originated in the chlamydomonas (C. reinhardtii). The choanoflagellates (Monosiga brevicollis) operate an elementary Hh pathway in expressing receptor Ptc (109). Various co-expressions of these genes guide the cell through its ontogenesis and final differentiation. The enriched mammalian genomes operate three Hh pathways (sonic, desert and indian), that evolved through gene duplication. In chronic lymphocytic leukemia, the Hh pathway enlists PI3K (110). In hepatocellular carcinoma of whatever etiology ( $B \& C$ viral; alcoholic cirrhosis) the Hh pathway is united with the Wnt/ß-catenin (vide supra) and North (vide infra) pathways with frequently silenced Dickkopf gene/protein (111).

Notch. The notch/Notch signaling pathway was functional in the ancestral cnidarians. The delta and serrate/jagged ligands-bound receptors, which are endocytosed and cleaved. Intracellular protein cleavage results in the fragments NICD (Notch intracellular domain). These are the DNA-binding proteins CSL (core binding factor, $\mathrm{CBF} /$ suppressor of hairless, SuH/lymphocyte activation gene, Lag2) directed at their targets. Involved are $\mathrm{Su}(\mathrm{H})$, Hairy and Enhancer of Split (Espl; HES, Drosophila), CBF/RBPЈ (recombination signal binding protein for $I g \kappa J)$, gene mastermind, mam/MAM and NF- $\mathrm{KB}$. Most of the Notch proteins are histone acetyltransferases; most acetylated genes are silenced. The Notch pathway is active in the embryos, larvae and planula of the extant $N$. vectensis. The Notch pathway regulates cell-to-cell communications, and the arising of neural precursors from epithelial cells. Ancestral early multicellular eukaryotic life forms (metazoa) utilized notch/Notch for nerve cell differentiation. The process was duplicated in $N$. vectensis by regulating the expression of gene Nvnotch. The Notch cascade suppressed neural differentiation markers; Notch inhibited the expression of differentiation inducer genes (among them some Nvsox genes). In $N$. vectensis appear the first achaete scute genes (chaete, bristle, Drosophila; plaque), which will be prominent in the protochordate amphioxus, represented by Branchiostoma floridae (112-114) (vide infra). In metazoa, Notch will run the vertebrate segmentation clock and generate secondary mesenchymal cells (115).

The human oncogenic dsDNA viruses activate notch/Notch. Human herpesvirus 8, Kaposi sarcoma herpesvirus (HHV8; KSHV) uses the Rta protein (replication transcription activation) as its lytic switch and RBPJK (recombination signal-binding protein-1 immunoglobulin kappa $\mathbf{J}$ region) is essential for the transactivation. The protein-folding cellular peptyl-prolyl cis/trans isomerase, 'never in mitosis' (Pin1) had been conserved from the yeast to the human genome, where it is a notch/Notch activator (and RBPJ $\kappa$ is a Notch effector), and as such it is overexpressed in some tumors (Kaposi sarcoma; adenocarcinomas). Co-opted by KSHV, Pin1 by direct binding, enhances the viral Rta transactivational functioning and protects Rta from autoubiquitylation, thus, contributing to Notch activation (view Fig. 6 of the cited article) (116). In primary effusion lymphoma cells KSHV and EBV commonly co-exist and activate the Notch signaling pathway (117). In HPV-induced squamous cell carcinomas activated Notch may be an aggravating or an alleviating factor (118). Observe: Kaposi sarcoma virologists use abbreviation vSOX for viral shut-off exonuclease, that has no connotation none whatsoever with eukaryotic stem cell proto-oncogene sox/Sox (vide infra).

Gamma secretase and ADAM proteases (A disintegrin and metalloprotease domain) cleave the Notch receptor; Delta and Jagged ligands activate it so, that its intracellular domain translocates into the nucleus. The ancient Notch pathway had been evolutionarily conserved. A major Notch

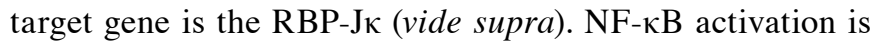
mediated by protein interaction with IKK $\alpha$ (inhibitory kappa kinase). Notch negatively interacting with tumor suppressor protein PTEN (phosphatase tensin chromosome ten), liberates PI3K/Akt from suppression, and opening up a pathway to mTOR activation. View Fig. 1 of the cited article (119). Hypoxia is a major activator of proto-oncogene Notch in glioblastoma (vide infra).

Sox. N. vectensis utilizes the ortholog of the coral Acrospora millepora's six sox/Sox pathways (sex determination region Y, SRY box). These transcription factor genes encode high mobility group proteins (HMGP) functioning in a wide range of developmental processes, gastrulation; and laying down ectoderm and endoderm. The sox genes co-exist in pluripotent stem cells with stem cell genes kfl (Krüppel factor-like); oct (octamer), c-myc (myelocytosis) and Nanog (rejuvenating celtic tribe). The SoxB stem cells of $N$. vectensis are positioned interstitially and encode three neural cell types: sensory neurons, ganglion neurons and nematocytes. Sox and Fox (forkhead box) genes cooperate in $N$. vectensis in germ layer specification and in the regulation of gastrulation (120-123).

The stem cell promoter proto-oncogene sox/Sox family members (SRY-related sex-determining factor on Y chromosome high mobility group box) are ancient transcription factors which exist in a family of over twenty proteins in the human genome/proteome. The Sox proteins functionally sustain stem cell pluripotentialities and act as generators of tissue anlagen 


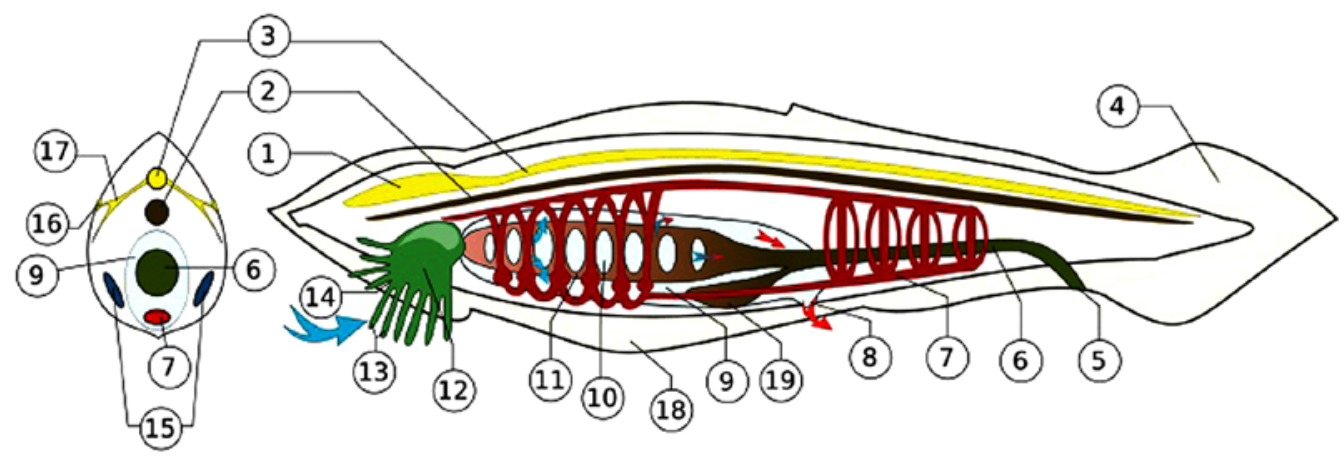

Figure 4. The amphioxus (represented by the Branchiostoma floridae of the Everglades) operates a nervous system consisting of peripheral sensory cells connected with the notochord by axons and synapses. Gamma aminobutyric acid and cholinergic molecular mediators circulate in the axons. The primordial achaete scute (Ash) genes/proteins (with Notch) were essential for the original encoding of the system. The ancestral Ash genes appear first in N. vectensis. Conserved up to the human genome, Ash gene homologs are proto-oncogenes for esthesioneuroblastoma of the olfactory ganglion, small cell undifferentiated carcinoma of the lung, and adenocarcinomas transforming into neuroectodermal tumors $(7,125)$. The depiction shown in the Figure, is from the files of Wikimedia Commons Information freely licensed media file repository, description page three. Permission is granted to copy this document under the terms of GNU Free Documentation License Version 1.2. 1, brain-like blister; 2, notochord; 3, dorsal nerve cord; 4, post-anal tail; 5, anus; 6, food canal; 7, blood system; 8 , abnominal porus; 9 , overpharynx lacuna; 10, gill's slit; 11, pharynx; 12, mouth lacuna; 13, mimosa; 14, mouth gap; 15, gonads (ovary/testicles); 16, light sensor; 17, nerves; 18, abdominal ply; 19, hepatic caecum.

in embryonic life, and as proto-oncogenes/oncogenes (example Sox 2/9) or tumor suppressor genes (example Sox7/15), or alternatingly both (example Sox2/4/9) in adult life. Some Sox proteins (Sox9/21) activate the oncogenic pathways Wnt; Gli; Hh; Notch. Sox 15/20 inhibit the Wnt pathway in pancreatic and other (testicular) cancer cells by dimerising with other oncoproteins (124).

Wnt. Unicellular eukaryotes do not operate the Wnt pathway. The Wnt pathway (wingless; Drosophila; integrated, mouse) in the ontogenesis of Ciona intestinalis was recently reviewed (125). Cnidarians and ctenophores in their ontogenesis utilize the Wnt pathway. Wnt ligands are secreted glycoproteins specific to their transmembrane receptors frizzled that trigger the $\beta$-catenin cascade by first liberating the $\beta$-catenin destroying unit from the control of disheveled. The $\beta$-catenin destruction unit consisting of proteins axin, glycogen synthase kinase (GSK) and an ancestral adenomatosis polyposis coli gene product in the cytoplasm is able to phosphorylate $\beta$-catenin, thus, marking it for ubiquitination. The cell rests. However, if unphosphorylated $\beta$-catenin is allowed to accumulate, it will translocate from the cytoplasm to the nucleus. There, it will by domain-attachment activate its target genes. Of numerous $\beta$-catenin target genes, genes tcfTCF/lefLEF are activated first ( $\mathrm{T}$ cell factor; lymphocyte enhancing factor). (Evolutionarily reviewed and extensively referenced in ref. 126,127).

$H h / W n t$. The hedgehog pathway is active in several human cancers and is potentially susceptible to small molecular inhibitors. Vismodegib induces remissions in advanced basal cell carcinoma due to inhibiting the Hh receptor smoothened (128). The antifungal itraconazole inhibits chemotherapy-resistant pancreatic adenocarcinoma cells (129). Natural products (cyclopamine, curcumin, epigallocatechin-3-gallate, genistein, norcantharidin, resveratrol and zerumbone) exert blockade in the sonic Hh pathway (130). The STAT/NF- $\mathrm{BB}$ pathway is suppressed by curcumin and epigallocatechin gallate (131). The basic nature of malignant transformation is to advance in several pathways, thus, rendering monotherapy often ineffective. The $\mathrm{Hh} / \mathrm{Gli}$ and the $\mathrm{Wnt} / \beta$-catenin pathways appear in combination (132). The sponge Amphimedon releases the antifungal cyclic peptide microsclerodermin (61). NF- $\kappa \mathrm{B}$ is constitutively activated in pancreatic adenocarcinoma cells. Microsclerodermin blocked NF- $\kappa \mathrm{B}$ production in pancreatic adenocarcinoma cells and forced cell death in the form of apoptosis (61). In the Wnt pathway, $\beta$-catenin and DNA methyltransferase (DNMT) co-localize in tumor cell nuclei. Lysine-specific demethylase (LSD), the regulator of DNMT, becomes a component of the complex. The DNMTs usually hypermethylate $\mathrm{CpG}$ islands and LSDs demethylate histones. The complex represses tumor suppressor genes and activate oncogenes (133).

CYPs. Cytochrome oxygenizers are expressed by the ligandactivated AhRs. CYP1 family proteins are overexpresed in $\mathrm{ER}^{+}$ human breast cancer cells. Considered to be co-carcinogens (breast cancer) due to their positive involvement in estrogen metabolism, production of procarcinogenic estrogen metabolites and induction of nucleotide polymorphism $(134,135)$.

ASC. Ernst Haeckel's works from 1876 are recently cited for placing the amphioxus (represented by the Branchiostoma floridae) (Fig. 4), at the base of vertebrate evolution (136). The amphioxus without duplicating its genome preserved the body image of its ancestors living 550 mya. It is not only being a cephalocordate that makes it unique. It has developed a large repertoire of TLRs, retained a large supply of transposable elements, and acquired the most ancient transposable elements of the adaptive immune system of vertebrate mammalians, one of the recombination activating genes, the RAG transposon (reviewed in ref. 137). The achaete scute (ASC, Drosophila) neurogenic pathway has taken its beginning in the Nematostella and reached an advanced stage in the amphioxus represented by the Branchiostoma floridae $(112,113)$. The human homolog of achaete scute encodes esthesioneuroblastoma, the malignant tumor of the olfactory ganglion, and converts adenocarcinoma cells into radiochemotherapy-resistant neuroectodermal 
cancers $(138,139)$. The neuroectodermal small cell bronchogenic carcinoma was treated long ago with cyclophosphamide, vincristine and doxorubicin. Short lasting remissions were induced at the price of toxicity; all remissions were lost to relapses. Immunostimulation with BCG (Bacille CalmetteGuréin) failed to improve results (140). Cisplatin improved remission rates, exerted toxicity, but failed to cure the disease. Targeting the causative oncogene/oncoprotein hASH with small molecular inhibitors and monoclonal antibodies raises the possibility to cure (141).

MicroRNAs exert post-translational control. The genomics and proteomics of the cnidaria cell enable it to practice siRNA inhibition of the NF- $\mathrm{NB}$ mRNA, and O-linked glycosylation of the NF- $\kappa \mathrm{B}$ protein molecule (vide supra), but all the target molecules thus diminished or overexpressed have not as yet been reported or even identified. In clinical medical oncology, naturally occurring and synthesized molecular inhibitors are applied for treatment (and encounter strong resistance by the NF- $\kappa$ B/STAT-transformed cancer cells) $(59,60)$.

The non-protein-coding RNAs (micro miRNAs; small interfering siRNAs; piwi-interacting piRNAs) exist and function in all eukaryotic cells primarily in post-translational downregulation of mRNA expression. Drosha, Dicer and Ago-piwi (argonaute; P-element-induced wimpy testis, Drosophila) RNAse, helicase and RNA polymerase enzymes carry out the specific alignment and degradation of the targeted mRNA molecules (142). Of the oldest miRs, only one, the miR-100 possessed by the cnidarian, $N$. vectensis, was passed through evolution to the human genome. Others, miR let-7 (the ancestor of the let family miRs), appeared in the first true bilaterians, the annelid Platynereis. Its antagonist Lin-28 expressed itself in the nematodes (Caenorhabditis) (143-146). All other genuine miRs the cnidarians preserved for themselves, and the descendant organisms generated their own new miRs. So much so, that the Hydra does not have miR-100. The hydra PIWI protein/ piRNA association represses transposon expressions that might threaten genomic integrity $(147,148)$.

In the human genome, the major effect of miR-100 is tumor growth suppression. In colon cancer, downregulation of miR-100 results in accelerated tumor cell growth $(149,150)$. The epithelial-to-mesenchymal transition of tumor cells (breast cancer) is an adverse prognostic event, except when it is induced by miR-100, in which case cessation of tumor cell growth follows (151). Upregulated expression of miR-100 attenuates glioma cell growth due to decreased expression of ATM (ataxia telangiectasia mutated) (152). In urothelial cancer of the urinary bladder, miR-100 suppressed oncogenes mTOR and SMARCA (mammalian target rapamycin; switch; sucrose non-fermentation; matrix-associated actin-dependent regulator chromatin-A) (153). Pancreatic cancer cells suppress miR-100; forced expression of miR-100 induced cessation of cancer cell proliferation in vivo in xenografts; miR-100 expression resulted in a blockade of fibroblast growth factor production (captured by its receptor, FGFR3), the major driver of tumor cells (154). In prostate cancer, miR-100 directly targets for downregulation of $\mathrm{AGO} 2 \mathrm{c}$ (argonaute) and thus blocks downregulation of miR-34a and miR-125b; these microRNAs suppress the expression of prostate cancer stem cells (155). In HeLa cells, an antagonism exists between the p53 and NF- $\kappa$ B proteins, in which the former blocks the latter in its intranuclear binding to the upstream sequence of the miR-100 gene (156). The presence of some of these elements in $N$. vectensis (miR-100), allows the presumption, that the entire human reaction originated in, and was inherited from, the cnidarian.

The miR let-7 and Lin28 antagonist-collaborator did not exist in the cnidarians; it was acquired and expanded to a family in the first true bilaterians and their successors, exhibiting itself in full in the nematode Caenorhabditis elegans (146), from where it continues its competition-collaboration in the human genome (157). There, it determines if chronic inflammatory processes will eventually terminate in oncogenesis (158). The oncogenic cascade is initiated by scr/SCR, Lin-28 and IL-6; let-7 is depleted; STAT3 and NF- $\kappa \mathrm{B}$ are co-activated and the process becomes irreversible (159).

See images of cnidarian pyruvate dehydrogenase kinase and hypoxia inducible factor in the internet (or in the original literature). The presence of STAT/NF- $\kappa$ B and STK, the srctype kinase, in the cnidarian cytoplasm (160) enables cells to live in the state that is recognized in the mammalian host as a chronic inflammatory process (the inflammasome) (158). Observe miRNAs regulating the relationship between host (scleratinian corals) and the Red Sea-isolate symbiont alga (Symbiodinium microadriaticum) forming a holobiont (161) (viral involvements received no comments in the study).

\section{Ctenophores}

Genomic proteomics of basal metazoans. At the stage of baseline diploblastic metazoans, beneath Cnidarians and Spongiae (162-164) lie the Placozoans, represented by Trichoplax adhaerens $(165,166)$, and the comb jelly Ctenophores, here by Mnemiopsis leidyi and Pleurobrachia pileus/bachei (167). These ctenophores are best characterized by missing genes, which are prominently present in other diploblastic metazoans. Ctenophores are devoid of Toll-like receptors and MyD88 signals. Hedgehogs and JAK/STATs are absent, but the numbers of homeodomain genes are in excess of other diploblasts. Acetylcholine, adrenaline, dopamine, histamine and serotonin are missing. Glutamate is a major signal molecule; it induces action potentials and currents. G-protein coupled neuropeptide receptors exist (without neurons). Ion channels carry stimuli. DNA methylation and demethylation are practiced. Argonaute units with Dicer are functional in the cytoplasm (167). The non-duplicated placozoan and cinadrian genomes carry the ancestral P450 cyp/ CYP sequences; so do the Spongiae (Amphimedon) (168). The unicellular choanoflagellates (Monosiga) do not show the presence of Runx genes/proteins. Single Runt domain Runx gene-product proteins are present in the placozoan Trichoplax, in the cnidarians and Spongiae (Amphimedon). While the Amphimedon genome encodes a Groucho protein, its Runx protein is devoid of the Groucho recruitment motif amino acid sequence WRPY (tryptophan; arginine; proline; tyrosine). Figs. 1 and 3 of the cited article (169) show that all the other listed organisms encoded this motif. The larva of the sea anemone Edwardsiella lineata parasitizes the ctenophore M. laidyi. The Edwardsiella NF- $\mathrm{KB}$ is ancestral 
to the split and a further evolved NF- $\mathrm{B}$ is operational in the non-parasitizing $N$. vectensis (vide supra) (170).

The ctenophore Wnt pathway imitates malignant transformation. Referenced in the Appendix of the volume in print (7), the ctenophore genome is shown encoding glycoprotein hormones (without glands), bone morphogenetic protein (BMP, without bones), platelet-derived growth factor (without platelets), nerve growth factor (without a nervous system), and the Wnt activator and BMP/TGF $\beta$-inhibitor norrin. Norrin is the ligand of the leucine-rich repeat-containing $\mathrm{G}$ protein-coupled receptor. The ctenophore Wnt pathway acts in an upregulated state driven by ligand-bound Frizzled and lipoprotein receptorrelated protein receptors, and dishevelled, that can inhibit by phosphorylation GSK-3 (glycogen synthase kinase). In the cytoplasmic ' $\beta$-catenin destructive complex', the active GSK-3 phosphorylates cytoplasmic $\beta$-catenin, thus sending it to ubiquitination. However, the inhibited GSK-3 allows excessive cytoplasmic accumulation of non-phosphorylated $\beta$-catenin, which translocates into the nucleus. There, it activates the promoters of its target genes, primarily tcf; tcfTCF/lefLEF are $\mathrm{T}$ cell factor and lymphocyte enhancing factor (without lymphocytes being in existence). In mammalian cells, TCF/LEF have become proto-oncogenes/oncoproteins. There, the target genes of the $\mathrm{TCF} / \mathrm{LEF}$ proteins are stimulatory to the cell cycle by PI3K/AKT and inhibitory to apoptosis by survivin (171). The complete vertebrate mammalian $\beta$-catenin destructive complex consists of GSK, axin and APC (adenomatous polyposis coli) gene product proteins. The ctenophore $\beta$-catenine destructive complex is deficient in that it is devoid of axin expression, and its GSK may act downregulated. The advanced mammalian Wnt pathway is antagonized by the tumor suppressor proteins Dickkopf (Drosophila). In Wnt carcinogenesis, the mammalian cell undergoing malignant transformation eliminates the Dickkopf genes (which suffer loss-of-function mutations). The ctenophores do not possess the Dickkopf genes. Thus, the ctenophore Wnt pathway is similar to that malignantly transformed vertebrate mammalian cells operate: the $\beta$-catenin destructive complex is weak in antagonizing the intranuclear transfer of $\beta$-catenin, thus, $\beta$-catenin readily translocates. Furthermore, natural inhibitors of the process, the Dickkopf proteins, are non-existent $(172,173)$.

The sox/Sox transcription factors maintain stemness of their host cells and operate by encoding high mobility group proteins. In the so-called tumor stem cells, they are active in association with other stem cell genes and proteins (Krüppelfactor; c-Myc; Nanog; Oct4) (vide infra). In the embryonic larval stage of ctenophores (Mnemiopsis; Pleurobrachia), several members of five major Sox gene groups perform essential regulatory functions for the directives of orderly ontogenesis (174). Extraordinary cell proliferations leading to deformities have not been observed. If some functions are constitutively encoded due to sox gene amplifications or gainof-function point mutations, that has not been as yet observed. However, in mammalian cells, the sox genes (and several other stem cell genes) are known to convert into proto-oncogenes (vide infra).

Wnt and Sox oncogenesis in human cells. Within the $\mathrm{Wnt} / \beta$-catenin oncogenic pathway in hepatocellular carcinoma cells, the mRNA of the tumor suppressor gene, Bednarek's WWOX (double tryptophan domain oxidoreductase), is demolished in the AGO complex by miR-153, which by aligning specifically to the WWOX mRNA 3'-untranslated region (UTR), destroys it. The cell cycle inhibitory protein WWOX will not be translated. The uninhibited intranuclearly transferred $\beta$-catenin binds to its target DNA gene promoters of the cell cycle (primarily to tcf/lef, vide supra) and constitutively activates them, to produce their oncoproteins TCF/LEF and others (175). WWOX plasmid induced WWOX protein expression in ovarian cancer stem cells. WWOX plasmid-treated ovarian cancer stem cells reduced, or ceased, the expression of, stem cell markers as follows: CD133, CD117, ATP-binding cassette $\mathrm{G}$ member2 protein, Nanog, Oct4 (octamer-binding transcription factor 4) and breast cancer resistance proteins (for which specific antibody is available at Chemicon, Billerica, CA, USA; cat. no. \#254515). A sign of differentiation induction was the increase of E-cadherin presentation (taking control of $\beta$-catenin at the inner cell membrane). The WWOX plasmid-treated cancer cells failed to grow in xenografts and lost their chemotherapy resistance. The DNA-binding WWOX protein of ancient derivation is naturally released from the mitochondria and translocates into the nucleus, where it interacts with TNF-related genes, oncogene Jun N-terminal kinase (reticuloendothelial virus 17 oncogene; in Japanese 17 is jun), being either inhibitory (to proto-oncogene jun) or promotional (to pro-apoptotic TNF and p53) (176).

In advanced multicellular organisms (including Homo), the cellular programing of twenty-some sox gene-product SOX proteins regulate the development of hematopoietic and central nervous systems in the embryo, and sustain pluripotency in their resting stem cells. Expressing their faculties constitutively, some sox/SOX proteins (human Sox2/9) transform individual cells into immortal and independent life forms (cancer cells), which overgrow and eventually kill their multicellular host. Other sox/SOX proteins (human Sox7) undergo methylation silencing it, so they may act as tumor suppressors. Such SOX proteins bind oncoproteins $\beta$-catenin or TCF, thus neutralizing them. If the sox/Sox protein resumes its cell polarity signaling, that is physiological in embryonic cells, in mature cells of a multicellular host, those cells will become metastasizing tumor cells. Tumor cells with certain downregulated sox/SOX proteins gain malignant potential, whereas tumor cells with overexpressed sox/SOX undergo attenuation (124). It is not known as yet which microRNAs influence translational expression of sox/SOX15. Many tumor-promoting or inhibitory circulating microRNAs are recognized in patients with cancer (177). Examples: miR-21 downregulating tumor suppressor PTEN (phosphatase and tensin homolog) and activating oncoprotein Akt (v-akt murine thymoma retroviral oncogene); the differentiation-inducer tumor suppressor miR let-7 (letter, lethal) are downregulated in many cancers (lethal when deleted); but SOX15 regulator miR has not been named as yet. In the early multicellular bilobular life forms (cnidarians; ctenophores), sox/Sox proteins serve in ontogenesis and in several cell survival pathways of their hosts. It appears that the ctenophore genome operates a weak $\beta$-catenin inhibitory system without inhibitors. If sox/Sox proteins sustain undifferentiated stem cells, the ctenophore genomes assume the imitation of an oncogenome arising in selected individual 
cells of an advanced multicellular host (including Homo). The sox/Sox 2 stem cell proto-oncogene promoted self-renewal, proliferation and chemoresistance in head and neck squamous carcinoma cells (178). Chemoradiotherapy-resistant stem cells arise in hypoxic regions of glioblastoma tumors. Hypoxia inducible factors, vascular endothelial growth factor (VEGF) and erythropoietin (EPO) accumulate in these regions. The tumor cells assume stem cell characteristics and upregulate notch/Notch proteins (179). Notch activation in hypoxia may be a fundamental ancient reaction of the cells living in anaerobic environment. When this fundamental faculty is resumed in single cells of a multicellular host, it may de-differentiate them to their ancestral pluripotentiality, physicochemical resistance, and independence from the community manifesting in incessant replicatory activity.

\section{Discussion}

Concerning the resistance of the Hydra and the Nematostella to algal symbionts, what has not been investigated and recognized is the ability of the invader Symbiodinia cells to inactivate the NF- $\mathrm{BB}$ pathway of the tolerant cnidarian host cell. One should conclude, if not proven otherwise, that zoochlorellae and zooxantellae cannot overcome the defensive $\mathrm{NF}-\kappa \mathrm{B}$ pathway in $H$. magnipapillata and $N$. vectensis. Could these symbiosis-resistant cnidarian genomes operate amplified or constitutively activated NF- $\mathrm{NB} / \mathrm{STAT}$ pathways, similarly to those of neoplastic cells, in order to achieve the state of resistance? Affirmatively, run-away uncontrollable cell replications tantamount to what will be referred to as malignant transformation in the subjects occupying higher ranks on the evolutionary scale do occur in the inhabitants of the lower echelons (180). The Porifera Acroporidae sponges are afflicted by the disease calicoblastic neoplasm. The proliferating cells evict their zooxantellae symbionts, and remain susceptible to apoptotic death induction. The ancestral p53 gene protects the Nematostella ( $N$. vectensis) by inducing apoptotic death of its proliferating germs cells (as referenced in 180).

Hundreds of million years of evolution enriched the ancient genomes. While retaining their basic faculties, the cnidarian NF- $\kappa$ B/STAT cell survival pathways phenomenally complicated themselves during their trajectory of 600 million years. As exercised in the human genome, the cell is rendered immortal by mutations and recombinations. An example is the complex encoding of a form of human acute myelogenous leukemia (181). The basic factor for immunosurveillance raised from the avian genome (v-rel avian reticuloendotheliosis viral oncogene homolog A) has become in the human genome constitutively expressed dimers, which as the NF- $\mathrm{B}$ p50/p65 Rel proto-oncogene/oncoprotein family residing in chromosome 11. The system is activated by RANK (receptor activator of NF- $\kappa \mathrm{B}$ ) to enable it to act as the conductor of the cascading orchestra consisting of members TNF $\alpha$, TRAF (TNF-receptor associated factor), STAT, IRF7 (interferon regulatory factor), TAK (TGF $\beta$-activated kinase), NIK (NF- $\kappa \mathrm{B}$-activated kinase), Bcl3 (B cell leukemia) and proto-oncogenes fos/Fos, jun/Jun, src/Src. The T cell leukemia virus (HTLV-1) Tax oncoprotein and the EBV and KSHV equivalent FLIP oncoproteins (FLICE-like caspase inhibitory protein; FADD-like IL-1 converting enzyme; Fas-associated death domain; factor apoptosis stimulating) activate the $\mathrm{NF}-\kappa \mathrm{B}$ pathway. At the 25 th year after its discovery, NF- $\kappa \mathrm{B}$ was recognized as a basic immunoregulator and as an oncoprotein $(182,183)$.

A complex network incorporating NF- $\kappa \mathrm{B}$ drives a form of acute human myeloid leukemia. Gain-of-function mutation of the $70 \mathrm{~kb} 21$ exon c-kit gene at 4q11-q12 (originally c-kit $\rightarrow$ v-kit of the Hardy-Zuckerman feline leukemia retrovirus) results in the encoding of the $145 \mathrm{kDa}$ KIT transmembrane protein receptor CD117, whose ligand is the stem cell factor. The overexpressed KIT activates Myc and RUNX1. KIT-activated MYC downregulates miR-29, and may induce the Wnt pathway. Its specific siRNA, and flavopiridol downregulate KIT. Furthermore, the kit promoter expresses binding sites for $\mathrm{NF}-\kappa \mathrm{B}$ and $\mathrm{Sp} 1$ (stimulating protein encoded from $12 \mathrm{p} 12-\mathrm{q} 13.1$ ), and thus NF- $\mathrm{B} / \mathrm{Sp} 1$ induce KIT overproduction. Sp1 inhibitor mithramycin, and $\mathrm{NF}-\kappa \mathrm{B}$ inhibitor Bay 11-7082 reduced KIT expression. Bortezomib induced Sp1 ubiquitination, and thus disrupted $\mathrm{Sp} 1 / \mathrm{NF}-\kappa \mathrm{B}$ interaction. Transactivation by the kit promoter $\mathrm{Sp} 1 / \mathrm{NF}-\kappa \mathrm{B}$ unison was abrogated, and thus KIT overproduction ceased. Bortezomib further inactivated oncoproteins STAT3, AKT, and ERK by appropriate serine and tyrosine phosphorylations. Codons 822- and 816-mutated KIT proteins are inhibited by imatinib and dasatinib, respectively. Furthermore, Spl was found to repress miR-29 transcription and so acted as antago-miR29, resulting in rising Sp1 levels; consequentially, KIT was upregulated. In reverse, bortezomib, mithramycin, or Bay 11-7082 downregulated KIT and SP1 and increased miR-29 expression. Spl and NF- $\mathrm{NB}$ have binding sites on the primary enhancer element of the miR-29 transcript on chromosome 7, and thus reduce miR-29 expression. In reverse, siRNA-induced knock-down of Sp1 and NF- $\mathrm{B}$ (p65) resulted in miR-29 upregulation. Bortezomib blocked the binding of Sp1/NF- $\kappa$ B to the miR-29 regulatory element on chromosome 7 , and thus induced miR-29 production; it also reduced c-Myc expression. Bortezomib downregulated $\mathrm{Sp} 1 / \mathrm{NF}-\kappa \mathrm{B}$, and upregulated miR-29b by disrupting the Sp1/NF- $\kappa$ B/HDAC complex. The hypophosphorylated KIT protein lost its leukemogenic potency. Furthermore, Sp1/NF- $\kappa \mathrm{B}$ and histone deacetylases (HDAC) interact. Enrichment of HDACs and SP1/NF- $\kappa \mathrm{B}$ on the miR-29 regulatory sequences occurs in concert. In effect, HDAC inhibition by its specific siRNA, or OSU-HDAC42 and MS275 resulted in upregulation of miR-29 transcription, with concurrent drop of Sp1 and KIT levels. Whereas HDAC expression resulted in downregulation of miR-29 and overproduction of Sp1/NF- $\kappa$ B. Intact $\mathrm{Sp} 1 / \mathrm{NF}-\kappa \mathrm{B}$ increased HDAC binding to the miR-29 enhancer region, whereas decreased such binding occurred when the Sp1/NF- $\mathrm{B}$ physical interaction was disrupted by the HDAC inhibitors. Upregulated miR-29 decreased the binding of the Sp1/NF- $\kappa$ B complex to the kit gene promoter. The leukemogenic oncogenes/oncoproteins could be so suppressed, NF- $\kappa$ B by Bay 11-7082, Sp1 by mithramycin, and HDAC by its inhibitor HDAC42; miR-29 acts by DNA methyltransferases; and bortezomib disrupts the oncoprotein complex of Sp1/NF- $\kappa \mathrm{B}$ (181).

When $\mathrm{NF}-\kappa \mathrm{B}$ is activated in melanoma, it suppresses phosphatase tensin homologue PTEN, and thus liberates oncoprotein $\mathrm{PI} 3 \mathrm{~K}$, an activator of proto-oncogenes Akt and/or mTOR. NF- $\mathrm{KB}$ would be inactivated by the SOCS (suppressor of cytokine signaling), were it not constitutively 
expressed (184). The natural substance capsaicin is an NF- $\mathrm{BB}$ inhibitor (185). Several synthetic small molecular PI3K inhibitors are ready for clinical trials (186). The FDA approved the small molecular PI3K inhibitor idelalisib first for lymphoma, lymphocytic leukemia, and as an investigational agent for metastatic breast carcinoma (187). Molecular kinase inhibitory therapy for the PI3K-driven rapidly replicating cancers (breast carcinoma) is to follow. The complex oncogenome of the breast cancer cell will not be switched off by single agent monotherapy (view Fig. 2 in the cited article) (188).

While the first cellular life forms succeeded in populating the ancient Earth by using the ancestors of the extant proto-oncogenes as cell survival pathways, the small molecular inhibitors synthesized now against the human cancer oncoproteins would probably render them defenseless first; but subsequent mutations could rescue their new small subpopulations to begin replicating again. Advanced protocols of combination chemotherapy and targeted therapy readily induce remissions, that are lost to relapses. Hundreds of million years of evolution superimposed an adaptive immune system over the preserved innate immune system (reviewed in refs. 90,137). Yet, infectious diseases are eradicated not by natural herd immunity, but rather by external interventions, such as preventive vaccinations. Is it possible that malignantly transformed cell populations could be eradicated by the immune system, even if the defensive cellular elements are the malignant cells themselves? The treatment modalities graftversus-leukemia (189) and HSCT (hematopoietic stem cell transplantations) induce remissions in survivors of treatment mortality, especially when re-enforced with NK cell, targeted chimeric antigen receptor- CAR-armed T cell, PD-L1-directed (programmed death, ligand) monoclonal antibody, or immunotoxin therapy (190). The best examples are the adoptive immune T- and NK lymphocyte-mediated protocols, the application of which eradicates malignant lymphomas and lymphocytic leukemias (191). In the leukemia-afflicted host, the native immune system does not mobilize an effective reaction for the rejection of malignantly proliferating cells. The elements for the rejection of the malignant cell population are there, but they are not assembled and are not self-applied. Properly assembled in the laboratory and administered sequentially, host immune reactions are capable of dissolving large masses of tumors (so much so that the patients are to be protected from life-threatening lymphokine storms and tumor lysis syndromes).

Predecessors of cnidarians and ctenophores survived physicochemical insults in the ancient Earth in a stage of autophagy. Malignantly transformed human cells (cancer cells) resist the effects of chemical and radiological agents in the stage of reversible autophagy followed by constitutively activated proto-oncogenes for survival and recovery. These cells will resist exposure to the same agents that induced the assumption of the autophagic stage. The clinical oncologists diagnose chemotherapy-resistant relapsed cancer. The practice of autophagy by the malignantly transformed cells in advanced multicellular hosts is a return to an atavistic physiological reaction widely exercised by the ancestors of cellular life on Earth.

The intracellular environment with operational p53, but absent MDM in the choanoflagellates, cnidarians and Spongiae might have been chronically inflammatory, and thus hyperactive, but not antiapoptotic. Their semblance to the malignantly transforming cells higher up on the evolutionary scale is comparable to the Wnt and NF- $\kappa$ B/STAT pathways, but not to the MDM anti-p53 pathway. Environmentally stressed predecessors, the virus-resistant cnidarians (Hydra magnipapillata; N. vectensis) might have initiated for their survival the scenario that occurs in advanced stages of the evolution, and manifests in cell survival by the Wnt, and NF- $\mathrm{KB} / \mathrm{STAT}$ co-activation, and the inhibition of pro-apoptotic p53/p60/p70 by MDM generation. That would be physiological metabolism in a stressed Ciona or amphioxus. When activated in some selected individual cells of arthropod, nematode, vertebrate piscine, reptilian, avian or mammalian (including human) hosts, these reactions may be viewed as a reversal to inherent ancient faculties conserved in their genomes $(7,125)$. The terminology for this condition in vertebrate hosts is the malignant disease cancer.

What was not available to deal with for the unicellular eukaryotic ancestors, is the multicellular host in which somatic cells, germ cells and stem cells coexist. There, if the malignant transformation was induced by an external pathogen (an oncogenic virus), the malignant cell has to withstand an immune attack by the host. Should the malignant transformation be induced endogenously by a LINE transposon, as referenced in (7), the malignant cell induces no immune reactions, or if it does, it is able to suppress them by the mobilization of stromal cell-derived factor chemokine CXC and its ligand CXCL12; Treg cells; myeloid-derived suppressor cells, and dendritic cells remaining undifferentiated and tolerogenic. Macrophages assuming M2 phenotypes, fibroblasts and endothelial cells rise for direct defense and support of the transformed cell. The transformed cell establishes cell-to-cell communications by surface membrane-to-surface membrane contacts, or by the release of microvesicle endosomes, all for its favor, within its microenvironment with fibroblasts, vascular endothelial cells, and M2 macrophages; microvesicles of tumor cell derivation de-activate immune T cells or even NK cells (125). The tumor cell evokes host tolerance by the production of IL-6, IL-10, IL-1 $\beta$ generating T17 lymphocytes, TGF $\beta$, prostaglandins and other factors regularly produced by syncytiotrophoblasts of the placenta, including IDO (indoleamine 2,3-dioxygenase) $(192,193)$. Thus, endogenously induced tumor cells receive full support for their growth and spread from their multicellular hosts. Human tumor cells grown in vitro in cultures, or as xenografts in athymic mice, lose this support. When tested for susceptibility to chemotherapeutical agents, or oncolytic viruses, these cells are defenseless and display deceivingly high sensitivity. No wonder, most of those treatment regimens fail to induce complete remissions in the environment of the natural hosts of the malignantly transformed cells in clinical trials conducted for the cure of cancer.

\section{Conclusion}

The primordial cell survival pathways that were assembled in the life forms in existence before and during the era of the the Cambrian sea enabled the establishment and expansion of eukaryotic cellular life on Earth. In extant descendants of all eukaryotic cells continuing in unicellular, or arranging for multicellular embodiments of life, the life survival pathways 
rendered basic services for the individuals in their ontogenesis and adult life, including the designs of body plans, generating haploid germ cells and retaining stem cells for the construction of organs, including a peripheral and a central nervous system, and for the replacement of aging somatic cells. In these advanced multicellular organisms, the cell survival pathways may revert to their phylo- and ontogenetically ancestral structure and function in a point-mutated constitutive manner, create new genes by fusions, and keep the cell in an immature, undifferentiated, individually independent and immortalized condition. Occurring in advanced multicellular hosts, these structures are recognized as proto-oncogenes and oncogenes and their gene products as oncoproteins. In becoming parasites of their differentiated multicellular hosts, these cells extract full support from their host, while exacting mortal consumption. The clinics diagnose the malady of cancer. The academic laboratories maintaining these immortal cell populations in culture recognize a close to indestructible ancient form of eukaryotic cellular life.

\section{References}

1. Sullivan JC and Finnerty JR: A surprising abundance of human disease genes in a simple 'basal' animal, the starlet sea anemone (Nematostella vectensis). Genome 50: 689-692, 2007.

2. Sullivan JC, Reitzel AM and Finnerty JR: A high percentage of introns in human genes were present early in animal evolution: Evidence from the basal metazoan Nematostella vectensis. Genome Inform 17: 219-229, 2006.

3. Putnam NH, Srivastava M, Hellsten U, Dirks B, Chapman J, Salamov A, Terry A, Shapiro H, Lindquist E, Kapitonov VV, et al: Sea anemone genome reveals ancestral eumetazoan gene repertoire and genomic organization. Science 317: 86-94, 2007.

4. Reitzel AM, Sullivan JC, Traylor-Knowles N and Finnerty JR Genomic survey of candidate stress-response genes in the estuarine anemone Nematostella vectensis. Biol Bull 214: 233-254, 2008

5. Goldstone JV: Environmental sensing and response genes in cnidaria: The chemical defensome in the sea anemone Nematostella vectensis. Cell Biol Toxicol 24: 483-502, 2008.

6. Nelson DR, Goldstone JV and Stegeman JJ: The cytochrome P450 genesis locus: the origin and evolution of animal cytochrome P450s. Philos Trans R Soc Lond B Biol Sci 368 20120474, 2013.

7. Sinkovics JG: RNA/DNA \& Cancer. Springer Verlag 2015 (In print).

8. Blanc G, Duncan G, Agarkova I, Borodovsky M, Gurnon J, Kuo A, Lindquist E, Lucas S, Pangilinan J, Polle J, et al: The Chlorella variabilis NC64A genome reveals adaptation to photosymbiosis, coevolution with viruses, and cryptic sex. Plant Cell 22: 2943-2955, 2010.

9. Vega Thurber RL, Barott KL, Hall D, Liu H, RodriguezMueller B, Desnues C, Edwards RA, Haynes M, Angly FE, Wegley L, et al: Metagenomic analysis indicates that stressors induce production of herpes-like viruses in the coral Porites compressa. Proc Natl Acad Sci USA 105: 18413-18418, 2008.

10. Davy SK, Allemand D and Weis VM: Cell biology of cnidariandinoflagellate symbiosis. Microbiol Mol Biol Rev 76: 229-261, 2012.

11. Grasis JA, Lachnit T, Anton-Erxleben F, Lim YW, Schmieder R, Fraune S, Franzenburg S, Insua S, Machado G, Haynes M, et al: Species-specific viromes in the ancestral holobiont Hydra.PLoS One 9: e109952, 2014

12. Sullivan JC, Wolenski FS, Reitzel AM, French CE, TraylorKnowles N, Gilmore TD and Finnerty JR: Two alleles of NF-kappaB in the sea anemone Nematostella vectensis are widely dispersed in nature and encode proteins with distinct activities. PLoS One 4: e7311, 2009.

13. Wolenski FS, Garbati MR, Lubinski TJ, Traylor-Knowles N, Dresselhaus E, Stefanik DJ, Goucher H, Finnerty JR and Gilmore TD: Characterization of the core elements of the NF- $\kappa \mathrm{B}$ signaling pathway of the sea anemone Nematostella vectensis. Mol Cell Biol 31: 1076-1087, 2011.
14. Armanious H, Gelebart P, Anand M, Belch A and Lai R: Constitutive activation of metalloproteinase ADAM10 in mantle cell lymphoma promotes cell growth and activates the TNFo/ NF-кB pathway. Blood 117: 6237-6246, 2011.

15. Martin AG and Fresno M: Tumor necrosis factor-alpha activation of NF-kappa B requires the phosphorylation of Ser-471 in the transactivation domain of c-Rel. J Biol Chem 275: 24383-24391, 2000.

16. Natoli G, Costanzo A, Moretti F, Fulco M, Balsano C and Levrero M: Tumor necrosis factor (TNF) receptor 1 signaling downstream of TNF receptor-associated factor 2. Nuclear factor kappaB (NFkappaB)-inducing kinase requirement for activation of activating protein 1 and NFkappaB but not of c-Jun $\mathrm{N}$-terminal kinase/stress-activated protein kinase. J Biol Chem 272: 26079-26082, 1997.

17. Lee S, Challa-Malladi M, Bratton SB and Wright CW: Nuclear factor- $\kappa \mathrm{B}$-inducing kinase (NIK) contains an amino-terminal inhibitor of apoptosis (IAP)-binding motif (IBM) that potentiates NIK degradation by cellular IAP1 (c-IAP1). J Biol Chem 289: 30680-30689, 2014.

18. Schaaf MJM, Willetts L, Hayes BP, Maschera B, Stylianou E and Farrow SN: The relationship between intranuclear mobility of the NF-kappaB subunit p65 and its DNA binding affinity. J Biol Chem 281: 22409-22420, 2006.

19. Adam E, Quivy V, Bex F, Chariot A, Collette Y, Vanhulle C, Schoonbroodt S, Goffin V, Nguyên TL-A, Gloire G, et al: Potentiation of tumor necrosis factor-induced NF- $\kappa$ B activation by deacetylase inhibitors is associated with a delayed cytoplasmic reappearance of I $\mathrm{B} \mathrm{B} \alpha$. Mol Cell Biol 23: 6200-6209, 2003.

20. Liongue $\mathrm{C}$ and Ward AC: Evolution of the JAK-STAT pathway. JAKSTAT 2: e22756, 2013.

21. Horvath CM: STAT proteins and transcriptional responses to extracellular signals. Trends Biochem Sci 25: 496-502, 2000.

22. Belyi VA, Ak P, Markert E, Wang H, Hu W, Puzio-Kuter A and Levine AJ: The origins and evolution of the p53 family of genes. Cold Spring Harb Perspect Biol 2: a001108, 2010.

23. Pankow $\mathrm{S}$ and Bamberger C: The $\mathrm{p} 53$ tumor suppressor-like protein nvp63 mediates selective germ cell death in the sea anemone Nematostella vectensis. PLoS One 2: e782, 2007.

24. Momand J, Villegas A and Belyi VA: The evolution of MDM2 family genes. Gene 486: 23-30, 2011.

25. Lane DP, Cheok CF, Brown C, Madhumalar A, Ghadessy FJ and Verma C: $\mathrm{Mdm} 2$ and $\mathrm{p} 53$ are highly conserved from placozoans to man. Cell Cycle 9: 540-547, 2010.

26. Biswas G, Anandatheerthavarada HK, Zaidi $M$ and Avadhani NG: Mitochondria to nucleus stress signaling: A distinctive mechanism of NFkappaB/Rel activation through calcineurin-mediated inactivation of IkappaBbeta. J Cell Biol 161: 507-519, 2003.

27. Amuthan G, Biswas G, Zhang SY, Klein-Szanto A, Vijayasarathy $\mathrm{C}$ and Avadhani NG: Mitochondria-to-nucleus stress signaling induces phenotypic changes, tumor progression and cell invasion. EMBO J 20: 1910-1920, 2001.

28. Hinz M, Lemke P, Anagnostopoulos I, Hacker C, Krappmann D, Mathas S, Dörken B, Zenke M, Stein H and Scheidereit C: Nuclear factor kappaB-dependent gene expression profiling of Hodgkin's disease tumor cells, pathogenetic significance, and link to constitutive signal transducer and activator of transcription 5a activity. J Exp Med 196: 605-617, 2002.

29. Nagy ZS, Rui H, Stepkowski SM, Karras J and Kirken RA: A preferential role for STAT5, not constitutively active STAT3, in promoting survival of a human lymphoid tumor. J Immunol 177: 5032-5040, 2006.

30. Fu L, Lin-Lee YC, Pham LV, Tamayo A, Yoshimura L and Ford RJ: Constitutive NF-kappaB and NFAT activation leads to stimulation of the BLyS survival pathway in aggressive B-cell lymphomas. Blood 107: 4540-4548, 2006.

31. Pham LV, Fu L, Tamayo AT, Bueso-Ramos C, Drakos E, Vega F, Medeiros LJ and Ford RJ: Constitutive BR3 receptor signaling in diffuse, large B-cell lymphomas stabilizes nuclear factor- $\kappa \mathrm{B}-$ inducing kinase while activating both canonical and alternative nuclear factor- $\kappa$ B pathways. Blood 117: 200-210, 2011.

32. Gebauer N, Hardel TT, Gebauer J, Bernard V, Merz H, Feller AC, Rades D, Biersack H, Lehnert $\mathrm{H}$ and Thorns C: Activating mutations affecting the NF-kappa B pathway and EZH2-mediated epigenetic regulation are rare events in primary mediastinal large B-cell lymphoma. Anticancer Res 34: 5503-5507, 2014. 
33. Odqvist L, Montes-Moreno S, Sánchez-Pacheco RE, Young KH, Martín-Sánchez E, Cereceda L, Sánchez-Verde L, Pajares R, Mollejo M, Fresno MF, et al: NF- $\kappa \mathrm{B}$ expression is a feature of both activated B-cell-like and germinal center B-cell-like subtypes of diffuse large B-cell lymphoma. Mod Pathol 27: 1331-1337, 2014

34. Demchenko YN and Kuehl WM: A critical role for the NF- $\mathrm{BB}$ pathway in multiple myeloma. Oncotarget 1: 59-68, 2010.

35. Litvinov IV, Cordeiro B, Fredholm S, Ødum N, Zargham H, Huang Y, Zhou Y, Pehr K, Kupper TS, Woetmann A, et al: Analysis of STAT4 expression in cutaneous T-cell lymphoma (CTCL) patients and patient-derived cell lines. Cell Cycle 13: 2975-2982, 2014.

36. Gelfanov VG, Burgess GS, Litz-Jackson S, King AJ, Marshall MS, Nakasatri H and Boswell HS: Transformation of interleukin-3-dependent cells without participation of Stat5/ bcl-xL: Cooperation leads to p65 nuclear factor $\kappa \mathrm{B}$-mediated apoptosis involving c-IAP2. Blood 98: 2508-2517, 2001.

37. Feuerhake F, Kutok JL, Monti S, Chen W, LaCasce AS, Cattoretti G, Kurtin P, Pinkus GS, de Leval L, Harris NL, et al: NFkappaB activity, function, and target-gene signatures in primary mediastinal large B-cell lymphoma and diffuse large B-cell lymphoma subtypes. Blood 106: 1392-1399, 2005.

38. Pont-Kingdon GA, Beagley CT, Okimoto $\mathrm{R}$ and Wolstenholme DR: Mitochondrial DNA of the sea anemone, Metridium senile (Cnidaria): Prokaryote-like genes for tRNA(fMet) and small-subunit ribosomal RNA, and standard genetic code specificities for AGR and ATA codons. J Mol Evol 39: 387-399, 1994

39. Beagley CT, Okimoto R and Wolstenholme DR: The mitochondrial genome of the sea anemone Metridium senile (Cnidaria) Introns, a paucity of tRNA genes, and a near-standard genetic code. Genetics 148: 1091-1108, 1998.

40. Kretz-Remy C, Munsch B and Arrigo AP: NFkappa B-dependent transcriptional activation during heat shock recovery. Thermolability of the NF-kappaB complex. J Biol Chem 276 : 43723-43733, 2001.

41. Starczynowski DT, Trautmann H, Pott C, Harder L, Arnold N, Africa JA, Leeman JR, Siebert R and Gilmore TD: Mutation of an IKK phosphorylation site within the transactivation domain of REL in two patients with B-cell lymphoma enhances REL's in vitro transforming activity. Oncogene 26: 2685-2694, 2007.

42. Thompson RC, Vardinogiannis I and Gilmore TD: Identification of an NF- $\mathrm{BB}$ p50/p65-responsive site in the human MIR155HG promoter. BMC Mol Biol 14: 24, 2013.

43. Lind EF, Elford AR and Ohashi PS: Micro-RNA 155 is required for optimal $\mathrm{CD}^{+} \mathrm{T}$ cell responses to acute viral and intracellular bacterial challenges. J Immunol 190: 1210-1216, 2013.

44. Netchiporouk E, Litvinov IV, Moreau L, Gilbert M, Sasseville D and Duvic M: Deregulation in STAT signaling is important for cutaneous T-cell lymphoma (CTCL) pathogenesis and cancer progression. Cell Cycle 13: 3331-3335, 2014.

45. Marosvári D, Téglási V, Csala I, Marschalkó M, Bödör C, Timár B, Csomor J, Hársing J and Reiniger L: Altered microRNA expression in folliculotropic and transformed mycosis fungoides. Pathol Oncol Res 21: 821-825, 2015.

46. Silva LM, Hirai KE, de Souza JR, Fuzii HT, Dias LB Jr, Carneiro FR, de Souza Aarão, TL and Quaresma JA: Immunohistochemical analysis of the expression of cellular transcription NFKB (p65). AP-1c-Fos and c-Jun and JAK/STAT in leprosy. Human Pathol 46: 746-752, 2015.

47. Ray PS, Sullivan JC, Jia J, Francis J, Finnerty JR and Fox PL: Evolution of function of a fused metazoan tRNA synthetase. Mol Biol Evol 28: 437-447, 2011.

48. Sinkovics JG, Howe CD and Shullenberger CC: Cellular activities in tissue culture of leukemic human bone marrow. Blood 24 389-401, 1964.

49. Baus D, Nonnenmacher F, Jankowski S, Döring C, Bräutigam C, Frank M, Hansmann ML and Pfitzner E: STAT6 and STAT1 are essential antagonistic regulators of cell survival in classical Hodgkin lymphoma cell line. Leukemia 23: 1885-1893, 2009

50. Canoz O, Rassidakis GZ, Admirand JH and Medeiros LJ Immunohistochemical detection of BCL-3 in lymphoid neoplasms: A survey of 353 cases. Mod Pathol 17: 911-917, 2004.

51. Cahir McFarland ED, Izumi KM and Mosialos G: Epstein-Barr virus transformation: Involvement of latent membrane protein 1-mediated activation of NF-kappaB. Oncogene 18: 6959-6964, 1999.
52. Espinoza JL, Takami A, Trung LQ, Kato $\mathrm{S}$ and Nakao $\mathrm{S}$ : Resveratrol prevents EBV transformation and inhibits the outgrowth of EBV immortalized human B cells. PLoS One 7: e1306, 2012.

53. Kashanchi F, Araujo J, Doniger J, Muralidhar S, Hoch R, Khleif S, Mendelson E, Thompson J, Azumi N, Brady JN, et al: Human herpesvirus 6 (HHV-6) ORF-1 transactivating gene exhibits malignant transforming activity and its protein binds to p53. Oncogene 14: 359-367, 1997.

54. Lacroix A, Collot-Teixeira S, Mardivirin L, Jaccard A, Petit B, Piguet C, Sturtz F, Preux P-M, Bordessoule D and RangerRogez S: Involvement of human herpesvirus- 6 variant B in classic Hodgkin's lymphoma via DR7 oncoprotein. Clin Cancer Res 16: 4711-4721, 2010

55. Sun Q, Matta H and Chaudhary PM: Kaposi's sarcoma associated herpes virus-encoded viral FLICE inhibitory protein activates transcription from HIV-1 Long Terminal Repeat via the classical NF-kappaB pathway and functionally cooperates with Tat. Retrovirology 2: 9, 2005.

56. Hussain AR, Ahmed SO, Ahmed M, Khan OS Al Abdulmohsen S, Platanias LC, Al-Kuraya KS and Uddin S: Cross-talk between NF- $\kappa \mathrm{B}$ and the PI3-kinase/AKT pathway can be targeted in primary effusion lymphoma (PEL) cell lines for efficient apoptosis. PLoS One 7: e39945, 2012.

57. Sun SC and Ballard DW: Persistent activation of NF-kappaB by the tax transforming protein of HTLV-1: Hijacking cellular IkappaB kinases. Oncogene 18: 6948-6958, 1999.

58. Shehata MF: Rel/Nuclear factor-kappa B apoptosis pathways in human cervical cancer cells. Cancer Cell Int 5: 10, 2005.

59. Németh ZH, Deitch EA, Szabó C and Haskó G: Pyrrolidinedithiocarbamate inhibits NF-kappaB activation and IL-8 production in intestinal epithelial cells. Immunol Lett 85: 41-46, 2003.

60. Wang W, Nag SA and Zhang R: Targeting the NF- $\kappa B$ signaling pathways for breast cancer prevention and therapy. Curr Med Chem 22: 264-289, 2015.

61. Guzmán EA, Maers K, Roberts J, Kemami-Wangun HV, Harmody D and Wright AE: The marine natural product microsclerodermin A is a novel inhibitor of the nuclear factor kappa $\mathrm{B}$ and induces apoptosis in pancreatic cancer cells. Invest New Drugs 33: 86-94, 2015.

62. Chan R, Gilbert M, Thompson KM, Marsh HN, Epstein DM and Pendergrast PS: Co-expression of anti-NFkappaB RNA aptamers and siRNAs leads to maximal suppression of NFkappaB activity in mammalian cells. Nucleic Acids Res 34: e36, 2006.

63. McKenna $S$ and Wright $C J$ : Inhibiting $I \kappa B \beta / N F-\kappa B$ signaling attenuates the expression of select pro-inflammatory genes. J Cell Sci 128: 2143-2155, 2015.

64. Chang HC, Lin KH, Tai YT, Chen JT and Chen RM: Lipoteichoic acid-induced TNF- $\alpha$ and IL- 6 gene expressions and oxidative stress production in macrophages are suppressed by ketamine through downregulating Toll-like receptor-mediated activation of ERK1/2 and NF-кB. Shock 33: 486-492, 2010.

65. García-Piñeres AJ, Castro V, Mora G, Schmidt TJ, Strunck E, Pahl HL and Merfort I: Cysteine 38 in p65/NF-kappaB plays a crucial role in DNA binding inhibition by sesquiterpene lactones. J Biol Chem 276: 39713-39720, 2001.

66. Liang MC, Bardhan S, Porco JA Jr and Gilmore TD: The synthetic epoxyquinoids jesterone dimer and epoxyquinone A monomer induce apoptosis and inhibit REL (human c-Rel) DNA binding in an IkappaBalpha-deficient diffuse large B-cell lymphoma cell line. Cancer Lett 241: 69-78, 2006.

67. Liang MC, Bardhan S, Pace EA, Rosman D, Beutler JA, Porco JA Jr and Gilmore TD: Inhibition of transcription factor NF-kappaB signaling proteins IKKbeta and p65 through specific cysteine residues by epoxyquinone A monomer: Correlation with its anti-cancer cell growth activity. Biochem Pharmacol 71: 634-645, 2006.

68. Ramakrishnan P, Clark PM, Mason DE, Peters EC, HsiehWilson LC and Baltimore D: Activation of the transcriptional function of the NF- $\kappa$ B protein c-Rel by O-GlcNAc glycosylation. Sci Signal 6: ra75, 2013.

69. Selvan N, Maiappa D, van den Toom HWP, Heck AJK, Ferenbach AT and van Aalten DMF: The early metazoan Trichoplax adhaerens possesses a functional O-GlcNAc system. J Biol Chem 250: 11969-11982, 2015. 
70. Sümegi M, Hunyadi-Gulyás E, Medzihradszky KF and Udvardy A: $26 \mathrm{~S}$ proteasome subunits are O-linked $\mathrm{N}$-acetylglucosamine-modified in Drosophila melanogaster. Biochem Biophys Res Commun 312: 1284-1289, 2003.

71. Heyne K, Winter C, Gerten F, Schmidt C and Roemer K: A novel mechanism of crosstalk between p53 and NF- $\mathrm{kB}$ pathways. Cell Cycle 12: 2479-2482, 2013.

72. Cha B, Lim JW and Kim H: Jak1/Stat3 is an upstream signaling of NF- $\kappa$ B activation in Helicobacter pylori-induced IL-8 production in gastric epithelial AGS cells. Yonsei Med J 56: 862-866, 2015.

73. Linher-Melville K, Haftchenary S, Gunning P and Singh G: Signal transducer and activator of transcription 3 and 5 regulate system Xc- and redox balance in human breast cancer cells. Mol Cell Biochem 405: 205-221, 2015.

74. Pramanik KC, Fofaria NM, Gupta P, Ranjan A, Kim SH and Srivastava SK: Inhibition of $\beta$-catenin signaling suppresses pancreatic tumor growth by disrupting nuclear $\beta$-catenin/TCF- 1 complex: Critical role of STAT-3. Oncotarget 6: 11561-11574, 2015.

75. Martinou JC and Kroemer G: Autophagy: Evolutionary and pathophysiological insights. Biochim Biophys Acta 1793: 1395-1396, 2009.

76. Katayama H, Kogure T, Mizushima N, Yoshimori T and Miyawaki A: A sensitive and quantitative technique for detecting autophagic events based on lysosomal delivery. Chem Biol 18 1042-1052, 2011.

77. Buzgariu W, Chera S and Galliot B: Methods to investigate autophagy during starvation and regeneration in hydra. Methods Enzymol 451: 409-437, 2008.

78. Chera S, Buzgariu W, Ghila L and Galliot B: Autophagy in Hydra: A response to starvation and stress in early animal evolution. Biochim Biophys Acta 1793: 1432-1443, 2009.

79. Dunn SR, Schnitzler CE and Weis VM: Apoptosis and autophagy as mechanisms of dinoflagellate symbiont release during cnidarian bleaching: Every which way you lose. Proc Biol Sci 274: 3079-3085, 2007.

80. Buss LW, Anderson C, Westerman E, Kritzberger C, Poudyal M, Moreno MA and Lakkis FG: Allorecognition triggers autophagy and subsequent necrosis in the cnidarian Hydractinia symbiolongicarpus. PLoS One 7: e48914, 2012.

81. Petersen HO, Höger SK, Looso M, Lengfeld T, Kuhn A, Warnken U, Nishimiya-Fujisawa C, Schnölzer M, Krüger M Ozbek S, et al: A comprehensive transcriptomic and proteomic analysis of hydra head regeneration. Mol Biol Evol: April, 2, 2015 (Epub ahead of print).

82. Galliot B: Autophagy and self-preservation: A step ahead from cell plasticity? Autophagy 2: 231-233, 2006.

83. Galliot B, Miljkovic-Licina M, Ghila L and Chera S: RNAi gene silencing affects cell and developmental plasticity in hydra. C R Biol 330: 491-497, 2007.

84. Chera S, de Rosa R, Miljkovic-Licina M, Dobretz K, Ghila L, Kaloulis $\mathrm{K}$ and Galliot B: Silencing of the hydra serine protease inhibitor Kazal1 gene mimics the human SPINK1 pancreatic phenotype. J Cell Sci 119: 846-857, 2006.

85. Räty S, Sand J, Laukkarinen J, Vasama K, Bassi C, Salvia R and Nordback I: Cyst fluid SPINK1 may help to differentiate benign and potentially malignant cystic pancreatic lesions Pancreatology 13: 530-533, 2013.

86. Lempinen M, Paju A, Kemppainen E, Smura T, Kylänpää ML, Nevanlinna H, Stenman J and Stenman UH: Mutations N34S and P55S of the SPINK1 gene in patients with chronic pancreatitis or pancreatic cancer and in healthy subjects: A report from Finland. Scand J Gastroenterol 40: 225-230, 2005.

87. Shimosegawa T, Kume K and Satoh K: Chronic pancreatitis and pancreatic cancer: Prediction and mechanism. Clin Gastroenterol Hepatol 7 (Suppl 11): S23-S28, 2009.

88. Koehler A, Desser S, Chang B, MacDonald J, Tepass U and Ringuette M: Molecular evolution of SPARC: Absence of the acidic module and expression in the endoderm of the starlet sea anemone, Nematostella vectensis. Dev Genes Evol 219: 509-521, 2009.

89. Fritzenwanker JH, Saina M and Technau U: Analysis of forkhead and snail expression reveals epithelial-mesenchymal transitions during embryonic and larval development of Nematostella vectensis. Dev Biol 275: 389-402, 2004.

90. Sinkovics JG: Horizontal gene transfers and cell fusions in microbiology, immunology and oncology (Review). Int J Oncol 35: 441-465, 2009.
91. Grant JL,Fishbein MC, Hong LS, Krysan K, Minna JD, Shay JW, Walser TC and Dubinett SM: A novel molecular pathway for Snail-dependent, SPARC-mediated invasion in non-small cell lung cancer pathogenesis. Cancer Prev Res (Phila) 7: 150-160, 2014.

92.Kaleağasığ lu F and Berger MR: SIBLINGs and SPARC families: Their emerging roles in pancreatic cancer. World $\mathrm{J}$ Gastroenterol 20: 14747-14759, 2014.

93. Yang F, Zhou X, Miao X, Zhang T, Hang X, Tie R, Liu N, Tian F, Wang $F$ and Yuan J: MAGEC2, an epithelial-mesenchymal transition inducer, is associated with breast cancer metastasis. Breast Cancer Res Treat 145: 23-32, 2014.

94. Sullivan JC, Sher D, Eisenstein M, Shigesada K, Reitzel AM, Marlow H, Levanon D, Groner Y, Finnerty JR and Gat U: The evolutionary origin of the Runx/CBFbeta transcription factors-studies of the most basal metazoans. BMC Evol Biol 8: 228 , 2008.

95. Klunker S, Chong MMW, Mantel PY, Palomares O, Bassin C, Ziegler M, Rückert B, Meiler F, Akdis M, Littman DR, et al: Transcription factors RUNX1 and RUNX3 in the induction and suppressive function of Foxp $3^{+}$inducible regulatory T cells. $\mathrm{J}$ Exp Med 206: 2701-2715, 2009.

96. Lück SC, Russ AC, Du J, Gaidzik V, Schlenk RF, Pollack JR, Döhner K, Döhner H and Bullinger L: KIT mutations confer a distinct gene expression signature in core binding factor leukaemia. Br J Haematol 148: 925-937, 2010.

97. Huang G, Zhao X, Wang L, Elf S, Xu H, Zhao X, Sashida G, Zhang Y, Liu Y, Lee J, et al: The ability of MLL to bind RUNX1 and methylate $\mathrm{H} 3 \mathrm{~K} 4$ at PU.1 regulatory regions is impaired by MDS/AML-associated RUNX1/AML1 mutations. Blood 118: 6544-6552, 2011.

98. Bledsoe KL, McGee-Lawrence ME, Camilleri ET, Wang X, Riester SM, van Wijnen AJ, Oliveira AM and Westendorf JJ: RUNX3 facilitates growth of Ewing sarcoma cells. J Cell Physiol 229: 2049-2056, 2014.

99. Hsu YL, Huang MS, Yang CJ, Hung JY, Wu LY and Kuo PL: Lung tumor-associated osteoblast-derived bone morphogenetic protein-2 increased epithelial-to-mesenchymal transition of cancer by Runx2/Snail signaling pathway. J Biol Chem 286: 37335-37346, 2011

100. Estécio MR, Maddipoti S, Bueso-Ramos C, DiNardo CD, Yang H, Wei Y, Kondo K, Fang Z, Stevenson W, Chang KS, et al: $R U N X 3$ promoter hypermethylation is frequent in leukaemia cell lines and associated with acute myeloid leukaemia inv(16) subtype. Br J Haematol 169: 344-351, 2015.

101. Martin JW, Zielenska M, Stein GS, van Wijnen AJ and Squire JA: The role of RUNX2 in osteosarcoma oncogenesis. Sarcoma 2011: 282745, 2011

102. Wang X, Goldstein D, Crowe PJ and Yang JL: Impact of STAT3 inhibition on survival of osteosarcoma cell lines. Anticancer Res 34: 6537-6545, 2014

103. Yang Q, Zhang S, Kang M, Dong R and Zhao J: Synergistic growth inhibition by sorafenib and cisplatin in human osteosarcoma cells. Oncol Rep 33: 2537-2544, 2015.

104. Sinkovics JG: Cytolytic Immune Lymphocytes. Schenk Buchverlag Passau, Germany; Dialog Campus, Budapest, p280, 2008.

105. Burgess $\mathrm{M}$ and Tawbi $\mathrm{H}$ : Immunotherapeutic approaches to sarcoma. Curr Treat Options Oncol 16: 345, 2015.

106. Matus DQ, Magie CR, Pang K, Martindale MQ and Thomsen GH: The Hedgehog gene family of the cnidarian, Nematostella vectensis, and implications for understanding metazoan Hedgehog pathway evolution. Dev Biol 313: 501-518, 2008

107. Bürglin TR: Evolution of hedgehog and hedgehog-related genes, their origin from Hog proteins in ancestral eukaryotes and discovery of a novel Hint motif. BMC Genomics 9: 127, 2008.

108. McCabe JM and Leahy DJ: Smoothened goes molecular: New pieces in the hedgehog signaling puzzle. J Biol Chem 290 3500-3507, 2015.

109. Warner JF, McCarthy AM, Morris RL and McClay DR: Hedgehog signaling requires motile cilia in the sea urchin. Mol Biol Evol 31: 18-22, 2014.

110. Kern D, Regl G, Hofbauer SW, Altenhofer P, Achatz G, Dlugosz A, Schnidar H, Greil R, Hartmann TN and Aberger F: Hedgehog/GLI and PI3K signaling in the initiation and maintenance of chronic lymphocytic leukemia. Oncogene, 2015. doi. org/10.1038/onc.2014.450. 
111. Giakoustidis A, Giakoustidis D, Mudan S, Sklavos A and Williams R: Molecular signalling in hepatocellular carcinoma: Role of and crosstalk among WNT/ $\beta$-catenin, Sonic Hedgehog, Notch and Dickkopf-1. Can J Gastroenterol Hepatol 29: 212-211, 2015.

112. Layden MJ and Martindale MQ: Non-canonical Notch signaling represents an ancestral mechanism to regulate neural differentiation. Evodevo 5: 30, 2014.

113. Layden MJ, Boekhout M and Martindale MQ: Nematostella vectensis achaete-scute homolog NvashA regulates embryonic ectodermal neurogenesis and represents an ancient component of the metazoan neural specification pathway. Development 139: 1013-1022, 2012.

114. Marlow H, Roettinger E, Boekhout M and Martindale MQ: Functional roles of Notch signaling in the cnidarian Nematostella vectensis. Dev Biol 362: 295-308, 2012.

115. Krejcí A and Bray S: Notch activation stimulates transient and selective binding of $\mathrm{Su}(\mathrm{H}) / \mathrm{CSL}$ to target enhancers. Genes Dev 21: 1322-1327, 2007.

116. Guito J and Lukac DM: KSHV reactivation and novel implications of protein isomerization on lytic switch control. Viruses 7 : 72-109, 2015.

117. Spadavecchia S, Gonzalez-Lopez O, Carroll KD, Palmeri D and Lukac DM: Convergence of Kaposi's sarcoma-associated herpesvirus reactivation with Epstein-Barr virus latency and cellular growth mediated by the notch signaling pathway in coinfected cells. J Virol 84: 10488-10500, 2010.

118. Rettig EM, Chung CH, Bishop JA, Howard JD, Sharma R, Li RJ, Douville C, Karchin R, Izumchenko E, Sidransky D, et al: Cleaved NOTCH1 expression pattern in head and neck squamous cell carcinoma is associated with NOTCH1 mutation, HPV status, and high risk features. Cancer Prev Res (Phila) 8 287-295, 2015

119. Ayaz F and Osborne BA: Non-canonical notch signaling in cancer and immunity. Front Oncol 4: 345, 2014

120. Jager M, Quéinnec E, Le Guyader H and Manuel M: Multiple Sox genes are expressed in stem cells or in differentiating neurosensory cells in the hydrozoan Clytia hemisphaerica. Evodevo 2: $12,2011$.

121. Shinzato C, Iguchi A, Hayward DC, Technau U, Ball EE and Miller DJ: Sox genes in the coral Acropora millepora: Divergent expression patterns reflect differences in developmental mechanisms within the Anthozoa. BMC Evol Biol 8: 311, 2008

122. Richards GS and Rentzsch F: Transgenic analysis of a SoxB gene reveals neural progenitor cells in the cnidarian Nematostella vectensis. Development 141: 4681-4689, 2014.

123. Magie CR, Pang K and Martindale MQ: Genomic inventory and expression of Sox and Fox genes in the cnidarian Nematostella vectensis. Dev Genes Evol 215: 618-630, 2005.

124. Thu KL, Becker-Santos DD, Radulovich N, Pikor LA, Lam WL and Tsao MS: SOX15 and other SOX family members are important mediators of tumorigenesis in multiple cancer types. Oncoscience 1: 326-335, 2014

125. Sinkovics JG: The cell survival pathways of the primordial RNA-DNA complex remain conserved in the extant genomes and may function as proto-oncogenes. Eur J Microbiol Immuno (Bp) 5: 25-43, 2015.

126. Ryan JF and Baxevanis AD: Hox, Wnt, and the evolution of the primary body axis: Insights from the early-divergent phyla. Biol Direct 2: 37, 2007.

127. Holstein TW: The evolution of the Wnt pathway. Cold Spring Harb Perspect Biol 4: a007922, 2012

128. Xin M: Hedgehog inhibitors: A patent review (2013 - present). Expert Opin Ther Pat 25: 549-565, 2015.

129. Lockhart NR, Waddell JA and Schrock NE: Itraconazole therapy in a pancreatic adenocarcinoma patient: A case report. J Oncol Pharm Pract: Feb, 9, 2015 (Epub ahead of print).

130. Huang YC, Chao KS, Liao HF and Chen YJ: Targeting sonic hedgehog signaling by compounds and derivatives from natural products. Evid Based Complement Alternat Med 2013: 748587, 2013

131. Chung SS and Vadgama JV: Curcumin and epigallocatechin gallate inhibit the cancer stem cell phenotype via down-regulation of STAT3-NF- $\mathrm{KB}$ signaling. Anticancer Res 35: 39-46, 2015.

132. Song L, Li ZY, Liu WP and Zhao MR: Crosstalk between Wnt/ $\beta$-catenin and Hedgehog/Gli signaling pathways in colon cancer and implications for therapy. Cancer Biol Ther 16: 1-7, 2015 .
133. a. Song J, Du Z, Ravasz M, Dong B, Wang Z and Ewing RM: A protein interaction between beta-catenin and Dnmtl regulates Wnt signaling and DNA methylation in colorectal cancer cells. Mol Cancer Res 13: 969-981, 2015.

b. Jin L, Hanigan CL, Wu Y, Wang W, Park BH, Woster PM and Casero RA: Loss of LSD1 (lysine-specific demethylase 1) suppresses growth and alters gene expression of human cancer cells in a p53- and DNMT1 (DNA methyltransferase 1)-independent manner. Biochem J 449: 459-468, 2013

134. Blackburn HL, Ellsworth DL, Shriver CD and Ellsworth RE Role of cytochrome P450 genes in breast cancer etiology and treatment: Effects on estrogen biosynthesis, metabolism, and response to endocrine therapy. Cancer Causes Control 26 319-332, 2015

135. Go RE, Hwang KA and Choi KC: Cytochrome P450 1 family and cancers. J Steroid Biochem Mol Biol 147: 24-30, 2015.

136. a. Yue JX, Yu JK, Putnam NH and Holland LZ: The transcriptome of an amphioxus, Asymmetron lucayanum, from the Bahamas: A window into chordate evolution. Genome Biol Evol 6: 2681-2696, 2014.

b. Lu TM, Luo YJ and Yu JK: BMP and Delta/Notch signaling control the development of amphioxus epidermal sensory neurons: Insights into the evolution of the peripheral sensory system. Development 139: 2020-2030, 2012.

137. Sinkovics JG: Horizontal gene transfers with or without cell fusions in all categories of the living matter. Adv Exp Med Biol 714: 5-89, 2011

138. Mhawech P, Berczy M, Assaly M, Herrmann F, Bouzourene H, Allal AS, Dulguerov P and Schwaller J: Human achaete-scute homologue (hASH1) mRNA level as a diagnostic marker to distinguish esthesioneuroblastoma from poorly differentiated tumors arising in the sinonasal tract. Am J Clin Pathol 122: 100-105, 2004

139. Carney ME, O'Reilly RC and Sholevar B: Buiakova 01, Lowry LD, Keane WM, Margolis FL and Rothstein JL: Expression of the human Achaete-scute 1 gene in olfactory neuroblastoma. J Neurooncol 26: 35-43, 1995.

140. Holoye PY, Samuels ML, Smith T and Sinkovics JG: Chemoimmunotherapy of small cell bronchogenic carcinoma. Cancer 42: 34-40, 1978.

141. Augustyn A, Borromeo M, Wang T, Fujimoto J, Shao C, Dospoy PD, Lee V, Tan C, Sullivan JP, Larsen JE, et al: ASCL1 is a lineage oncogene providing therapeutic targets for highgrade neuroendocrine lung cancers. Proc Natl Acad Sci USA 111: 14788-14793, 2014

142. Shabalina SA and Koonin EV: Origins and evolution of eukaryotic RNA interference. Trends Ecol Evol 23: 578-587, 2008.

143. Christodoulou F, Raible F, Tomer R, Simakov O, Trachana K, Klaus S, Snyman H, Hannon GJ, Bork P and Arendt D: Ancient animal microRNAs and the evolution of tissue identity. Nature 463: 1084-1088, 2010.

144. Grimson A, Srivastava M, Fahey B, Woodcroft BJ, Chiang HR, King N, Degnan BM, Rokhsar DS and Bartel DP: Early origins and evolution of microRNAs and Piwi-interacting RNAs in animals. Nature 455: 1193-1197, 2008.

145. Hertel J, Bartschat S, Wintsche A, Otto C and Stadler PF; Students of the Bioinformatics Computer Lab: Evolution of the let-7 microRNA family. RNA Biol 9: 231-241, 2012.

146. Ambros V: A hierarchy of regulatory genes controls a larva-toadult developmental switch in C. elegans. Cell 57: 49-57, 1989.

147. Krishna S, Nair A, Cheedipudi S, Poduval D, Dhawan J, Palakodeti D and Ghanekar Y: Deep sequencing reveals unique small RNA repertoire that is regulated during head regeneration in Hydra magnipapillata. Nucleic Acids Res 41: 599-616, 2013.

148. Juliano CE, Reich A, Liu N, Götzfried J, Zhong M, Uman S, Reenan RA, Wessel GM, Steele RE and Lin H: PIWI proteins and PIWI-interacting RNAs function in Hydra somatic stem cells. Proc Natl Acad Sci USA 111: 337-342, 2014

149. Chen P, Xi Q, Wang Q and Wei P: Downregulation of microRNA100 correlates with tumor progression and poor prognosis in colorectal cancer. Med Oncol 31: 235, 2014.

150. Peng H, Luo J, Hao H, Hu J, Xie SK, Ren D and Rao B MicroR NA-100 regulates SW620 colorectal cancer cell proliferation and invasion by targeting RAP1B. Oncol Rep 31: 2055-2062, 2014.

151. Chen D, Sun Y, Yuan Y, Han Z, Zhang P, Zhang J, You MJ, Teruya-Feldstein J, Wang M, Gupta S, et al: miR-100 induces epithelial-mesenchymal transition but suppresses tumorigenesis, migration and invasion. PLoS Genet 10: e1004177, 2014. 
152. Ng WL, Yan D, Zhang X, Mo YY and Wang Y: Over-expression of miR-100 is responsible for the low-expression of ATM in the human glioma cell line: M059J. DNA Repair (Amst) 9: 1170-1175, 2010.

153. Morais DR, Reis ST, Viana N, Piantino CB, Massoco C, Moura C, Dip N, Silva IA, Srougi M and Leite KRM: The involvement of miR-100 in bladder urothelial carcinogenesis changing the expression levels of mRNA and proteins of genes related to cell proliferation, survival, apoptosis and chromosomal stability. Cancer Cell Int 14: 119, 2014.

154. Li Z, Li X, Yu C, Wang M, Peng F, Xiao J, Tian R, Jiang J and Sun C: MicroRNA-100 regulates pancreatic cancer cells growth and sensitivity to chemotherapy through targeting FGFR3. Tumour Biol 35: 11751-11759, 2014

155. Wang M, Ren D, Guo W, Wang Z, Huang S, Du H, Song L and Peng X: Loss of miR-100 enhances migration, invasion, epithelial-mesenchymal transition and stemness properties in prostate cancer cells through targeting Argonaute 2. Int J Oncol 45: 362-372, 2014.

156. Ghose $\mathrm{J}$ and Bhattacharyya NP: Transcriptional regulation of

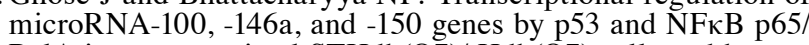
RelA in mouse striatal STHdh(Q7)/ Hdh(Q7) cells and human cervical carcinoma HeLa cells. RNA Biol 12: 457-477, 2015.

157. Ma X, Li C, Sun L, Huang D, Li T, He X, Wu G, Yang Z, Zhong X, Song L, et al: Lin28/let-7 axis regulates aerobic glycolysis and cancer progression via PDK1. Nat Commun 5: 5212, 2014.

158. Sinkovics JG: Molecular biology of oncogenic inflammatory processes. I. Non-oncogenic and oncogenic pathogens, intrinsic inflammatory reactions without pathogens, and microRNA/ DNA interactions (Review). Int J Oncol 40: 305-349, 2012

159. Iliopoulos D, Hirsch HA and Struhl K: An epigenetic switch involving NF-kappaB, Lin28, Let-7 MicroRNA, and IL6 links inflammation to cell transformation. Cell 139: 693-706, 2009.

160. Bosch TC, Unger TF, Fisher DA and Steele RE: Structure and expression of STK, a src-related gene in the simple metazoan Hydra attenuata. Mol Cell Biol 9: 4141-4151, 1989.

161. Baumgarten S, Bayer T, Aranda M, Liew YJ, Carr A, Micklem G and Voolstra CR: Integrating microRNA and mRNA expression profiling in Symbiodinium microadriaticum, a dinoflagellate symbiont of reef-building corals. BMC Genomics 14: 704, 2013.

162. Ruiz-Ramos DV and Baums IB: Microsatellite abundance across the Anthozoa and Hydrozoa in the phylum Cnidaria. BMC Genomics 15: 939, 2014.

163. Srivastava M, Simakov O, Chapman J, Fahey B, Gauthier ME, Mitros T, Richards GS, Conaco C, Dacre M, Hellsten U, et al: The Amphimedon queenslandica genome and the evolution of animal complexity. Nature 466: 720-726, 2010.

164. Kerner P, Degnan SM, Marchand L, Degnan BM and Vervoort M: Evolution of RNA-binding proteins in animals: Insights from genome-wide analysis in the sponge Amphimedon queenslandica. Mol Biol Evol 28: 2289-2303, 2011.

165. Srivastava M, Begovic E, Chapman J, Putnam NH, Hellsten U, Kawashima T, Kuo A, Mitros T, Salamov A, Carpenter ML, et al: The Trichoplax genome and the nature of placozoans. Nature 454: 955-960, 2008.

166. Schierwater B, de Jong D and Desalle R: Placozoa and the evolution of Metazoa and intrasomatic cell differentiation. Int $J$ Biochem Cell Biol 41: 370-379, 2009

167. Moroz LL, Kocot KM, Citarella MR, Dosung S, Norekian TP Povolotskaya IS, Grigorenko AP, Dailey C, Berezikov E, Buckley KM, et al: The ctenophore genome and the evolutionary origins of neural systems. Nature 510: 109-114, 2014.

168. Nelson DR, Goldstone JV and Stegeman JJ: The cytochrome P-450 genesis locus: the origin and evolution of animal cytochrome P450. Philos Trans R Soc Lond B Biol Sci 368: 20120474, 2013

169. Robertson AJ, Larroux C, Degnan BM and Coffman JA: The evolution of Runx genes II. The C-terminal Groucho recruitment motif is present in both eumetazoans and homoscleromorphs but absent in a haplosclerid demosponge. BMC Res Notes 2: 59 , 2009.

170. Stefanik DJ, Lubinski TJ, Granger BR, Byrd AL, Reitzel AM, DeFilippo L, Lorenc A and Finnerty JR: Production of a reference transcriptome and transcriptomic database (EdwardsiellaBase) for the lined sea anemone, Edwardsiella lineata, a parasitic cnidarian. BMC Genomics 15: 71, 2014.
171. Fernández JG, Rodríguez DA, Valenzuela M, Calderon $\mathrm{C}$, Urzúa U, Munroe D, Rosas C, Lemus D, Díaz N, Wright MC, et al: Survivin expression promotes VEGF-induced tumor angiogenesis via PI3K/Akt enhanced $\beta$-catenin/Tcf-Lef dependent transcription. Mol Cancer 13: 209, 2014.

172. Jager M, Dayraud C, Mialot A, Quéinnec E, le Guyader H and Manuel M: Evidence for involvement of Wnt signalling in body polarities, cell proliferation, and the neuro-sensory system in an adult ctenophore. PLoS One 8: e84363, 2013.

173. Pang K, Ryan JF, Mullikin JC, Baxevanis AD and Martindale MQ; NISC Comparative Sequencing Program: Genomic insights into Wnt signaling in an early diverging metazoan, the ctenophore Mnemiopsis leidyi. Evodevo 1: 10, 2010.

174. Schnitzler CE, Simmons DK, Pang K, Martindale MQ and Baxevanis AD: Expression of multiple Sox genes through embryonic development in the ctenophore Mnemiopsis leidyi is spatially restricted to zones of cell proliferation. Evodevo 5: 15, 2014.

175. Hua HW, Jiang F, Huang Q, Liao Z and Ding G: MicroRNA-153 promotes $\mathrm{Wnt} / \beta$-catenin activation in hepatocellular carcinoma through suppression of WWOX. Oncotarget 6: 3840-3847, 2015.

176. Yan HC, Xu J, Fang LS, Qiu YY, Lin XM, Huang HX and Han QY: Ectopic expression of the WWOX gene suppresses stemness of human ovarian cancer stem cells. Oncol Lett 9: 1614-1620, 2015.

177. Ma R, Jiang T and Kang X: Circulating microRNAs in cancer: Origin, function and application. J Exp Clin Cancer Res 31: 38 , 2012.

178. Lee SH, Oh S-Y, Do SI, Lee HJ, Kang HJ, Rho YS, Bae WJ and Lim YC: SOX2 regulates self-renewal and tumorigenicity of stem-like cells of head and neck squamous cell carcinoma. Br J Cancer 111: 2122-2130, 2014

179. Irshad K, Mohapatra SK, Srivastava C, Garg H, Mishra S, Dikshit B, Sarkar C, Gupta D, Chandra PS, Chattopadhyay P, et al: A combined gene signature of hypoxia and notch pathway in human glioblastoma and its prognostic relevance. PLoS One 10: e0118201, 2015.

180. Robert J: Comparative study of tumorigenesis and tumor immunity in invertebrates and nonmammalian vertebrates. Dev Comp Immunol 34: 915-925, 2010.

181. Liu S, Wu LC, Pang J, Santhanam R, Schwind S, Wu YZ, Hickey CJ, Yu J, Becker H, Maharry K, et al: Sp1/NFkappaB/ HDAC/miR-29b regulatory network in KIT-driven myeloid leukemia. Cancer Cell 17: 333-347, 2010.

182. Ghosh S and Hayden MS: Celebrating 25 years of $N F-\kappa B$ research. Immunol Rev 246: 5-13, 2012.

183. Xiao G and Fu J: NF- $\mathrm{B}$ and cancer: A paradigm of Yin-Yang. Am J Cancer Res 1: 192-221, 2011.

184. Ueda Y and Richmond A: NF-kappaB activation in melanoma. Pigment Cell Res 19: 112-124, 2006.

185. Patel PS, Varney ML, Dave BJ and Singh RK: Regulation of constitutive and induced NF-kappaB activation in malignant melanoma cells by capsaicin modulates interleukin- 8 production and cell proliferation. J Interferon Cytokine Res 22: 427-435, 2002.

186. Martini M, Ciraolo E, Gulluni F and Hirsch E: Targeting PI3K in cancer: Any good news? Front Oncol 3: 108, 2013.

187. Editorial. FDA approves PI3K inhibitor, idelalisib for treatment of relapsed CLL, follicular jymphoma and small lymphocytic lymphoma, Science \& Education on Oncology PRO http:// oncologypro.esmo.org

188. Mukohara T: PI3K mutations in breast cancer: prognostic and therapeutic implications. Breast Cancer 7: 111-123, 2015.

189. Sinkovics JG: Antileukemia and antitumor effects of the graftversus-host disease: A new immunovirological approach. Acta Microbiol Immunol Hung 57: 253-347, 2010.

190. Geiger TL and Rubnitz JE: New approaches for the immunotherapy of acute myeloid leukemia. Discov Med 19: 275-284, 2015.

191. Magee MS and Snook AE: Challenges to chimeric antigen receptor (CAR)-T cell therapy for cancer. Discov Med 18: 265-271, 2014.

192. Sinkovics JG and Horvath JC: Human natural killer cells: A comprehensive review. Int J Oncol 27: 5-47, 2005.

193. Bruchard M and Ghiringhelli F: Microenvironment tumoral. Cellules régulatrices et cytokines immunosuppressives. Med Sci 30: 429-435, 2014. 


\section{Note added in proof}

An extraordinary observation concerns the evolution of tumor necrosis factors (mentioned among Death Factors in Fig. 2). The human TNF- $\alpha$, as the ligand of its receptors R1 and R2, activates different cytoplasmic pathways. R1 releases NF- $\mathrm{NB}$ from its cytoplasmic anchor I $\mathrm{I} B$, thus allowing its transfer to the nucleus for the activation of its numerous pro-inflammatory and proto-oncogenic target genes. This receptor activates also cytoplasmic MAP3K (mitogene-activated protein kinase). Further, commands emanating from R1 travel either toward SODD (silencer of death domains), or to FADD (factor apoptosis stimulator Fas-associated death domain), and to activation of caspases $8 / 3$. This latter effect culminating in apoptosis induction was responsible for the unforgettable sensational first introduction of the newly discovered 'tumor necrosis factor' molecule in the mid-1970's (194). Pathways activated by R2 are those of VEGF-R2 (vascular endothelial growth factor receptor) and PI3K (phosphatidylinositol kinase) (195). The ancestor of the human system was installed in the pre-Cambrian cnidarian corals Acropora, and remains conserved throughout over 550 million years of evolution in both the cnidarian and human genomes. The human TNF- $\alpha$ induces apoptosis by myosin fragmentation in the extant cnidarian coral cells, and vice versa: the cnidarian TNF equivalent remains an apoptosis-inducer in human (WT-immortalized Jurkat T-lymphocytes) cells, both operating through the FADD pathway (196). The derivation and the evolutionary conservation of proto-oncogenes, from the ancestral unicellular eukaryotes on, have been recognized early: yeasts and amoebae (the Dictyostelium) operate the ancestral ras proto-oncogenes (197).

\section{References}

194. Old LJ: Tumor necrosis factor (TNF). Science 230: 630-632, 1985. 195. Urschel K and Cicha I: TNF- $\alpha$ in the cardiovascular system: from physiology to therapy. Internat J Interferon Cytokine Med Res 7: 9-25, 2015.

196. Quistad SD, Stotland A, Barott KL, Smurthwaite CA, Hilton BJ, Grasis JA, Wolkowicz R and Rohwer FL: Evolution of TNF-induced apoptosis reveals $550 \mathrm{My}$ functional conservation. Proc Natl Acad Sci USA 111: 9567-9572, 2014.

197. Spandidos DA and Lang JC: In vitro cell transformation by ras oncogenes. Crit Rev Oncog 1: 195-209, 1989.

\section{Addendum}

Int J Oncol 19: 473-488, 2001; DOI: 10.3892/ijo.19.3.473

The authors would like to acknowledge that the Coriphosphine $\mathrm{O}$ stain shown in the upper panel of Figure 8 was a kind gift from Dr T.P. Loughran of the H.L. Moffitt Cancer Center, Tampa, FL, USA. 